\title{
Model for Atomic Oxygen Visible Line Emissions in Comet C/1995 O1 Hale-Bopp
}

\author{
Susarla Raghuram* and Anil Bhardwaj ${ }^{\dagger}$ \\ Space Physics Laboratory, Vikram Sarabhai Space Center, Trivandrum, 695022, India.
}

May 26, 2022

\section{त}

\section{Abstract}

NWe have recently developed a coupled chemistry-emission model for the green $(5577 \AA)$ and red-doublet $(6300,6364$ Å) emissions of atomic oxygen on comet C/1996 B2 Hyakutake. In the present work we applied our model to comet C/1995 O1 Hale-Bopp, which had an order of magnitude

Whigher $\mathrm{H}_{2} \mathrm{O}$ production rate than comet Hyakutake, to evaluate the photochemistry associated with the production and loss of $\mathrm{O}\left({ }^{1} \mathrm{~S}\right)$ and $\mathrm{O}\left({ }^{1} \mathrm{D}\right)$ atoms and emission processes of green and red-doublet lines. We present the wavelength-dependent - photo-attenuation rates for different photodissociation processes forming $\mathrm{O}\left({ }^{1} \mathrm{~S}\right)$ and $\mathrm{O}\left({ }^{1} \mathrm{D}\right)$. The calculated radiative efficiency profiles of $\mathrm{O}\left({ }^{1} \mathrm{~S}\right)$ and $\mathrm{O}\left({ }^{1} \mathrm{D}\right)$ atoms show that in comet Hale-Bopp the green and red-doublet emissions are emitted mostly above radial distances of $10^{3}$ and $10^{4} \mathrm{~km}$, respectively. The model calculated [OI] $6300 \AA$ emission surface brightness and average intensity over the Fabry-Pérot spectrometer field of view are consistent with the observation of Morgenthaler et al. (2001), while the intensity ratio of green to red-doublet emission is in agreement with the observation of Zhang et al. (2001). In comet Hale-Bopp, for cometocentric distances less than $10^{5} \mathrm{~km}$, the intensity of [OI] $6300 \AA$ line is mainly governed by photodissociation of $\mathrm{H}_{2} \mathrm{O}$. Beyond $10^{5} \mathrm{~km}$, $-\mathrm{O}\left({ }^{1} \mathrm{D}\right)$ production is dominated by photodissociation of the water photochemical daughter product $\mathrm{OH}$. Whereas the [OI] \5577 A emission line is controlled by photodissociation of both $-\mathrm{H}_{2} \mathrm{O}$ and $\mathrm{CO}_{2}$. The calculated mean excess energy in various $>$ photodissociation processes show that the photodissociation of $\mathrm{CO}_{2}$ can produce $\mathrm{O}\left({ }^{1} \mathrm{~S}\right)$ atoms with higher excess velocity compared to the photodissociation of $\mathrm{H}_{2} \mathrm{O}$. Thus, our model calculations suggest that involvement of multiple sources in the formation of $\mathrm{O}\left({ }^{1} \mathrm{~S}\right)$ could be a reason for the larger width of green line than that of red-doublet emission lines observed in several comets.

\section{Introduction}

Owing to its very high $\mathrm{H}_{2} \mathrm{O}$ production rate, $\mathrm{C} / 1995$ O1 HaleBopp was a great comet in the night sky of the year 1997. The visible emissions of atomic oxygen ([OI] 6300, 6364, and $5577 \AA$ ), which are accessible to the ground-based optical instruments, have been observed by Morgenthaler et al. (2001)

\footnotetext{
*raghuramsusarla@gmail.com

†anil_bhardwaj@vssc.gov.in; bhardwaj_spl@yahoo.com
}

and Zhang et al. (2001) in the coma of Hale-Bopp. Since the lifetime of oxygen atom in the ${ }^{1} \mathrm{D}$ metastable state is relatively small $(\sim 110 \mathrm{~s})$ compared to the photochemical lifetime of $\mathrm{H}_{2} \mathrm{O}\left(\sim 8 \times 10^{4} \mathrm{~s}\right)$, it cannot travel larger distances in the coma without decaying to the ground ${ }^{3} \mathrm{P}$ state. Moreover, most of the production of oxygen in the ${ }^{1} \mathrm{D}$ state is through photodissociative excitation of $\mathrm{H}_{2} \mathrm{O}$ (Bhardwaj and Haider, 2002). Thus, [OI] $6300 \AA$ emission has been used to trace the spatial distribution as well as to quantify the production rate of $\mathrm{H}_{2} \mathrm{O}$ in several comets (Delsemme and Combi, 1976; Delsemme and Combi, 1979; Fink and Johnson, 1984; Schultz et al., 1992; Morgenthaler et al., 2001; Furusho et al., 2006; Fink, 2009).

Based on the study of Festou and Feldman (1981) the intensity ratio of green $(5577 \AA)$ to red-doublet $(6300 \AA$ and $6364 \AA)$ emissions (here after $\mathrm{G} / \mathrm{R}$ ratio) of atomic oxygen has been used to determine whether the parent source of these lines is $\mathrm{H}_{2} \mathrm{O}$ or $\mathrm{CO}_{2} / \mathrm{CO}$ in the coma of comets (Cochran, 1984, 2008; Morrison et al., 1997; Zhang et al., 2001; Cochran and Cochran, 2001; Furusho et al., 2006; Capria et al., 2005, 2008, 2010; McKay et al., 2012a,b). The modelling studies of these emissions in comets showed that photodissociative excitation of $\mathrm{H}_{2} \mathrm{O}$ is the major production process of the [OI] $6300 \AA$ emission (Festou and Feldman, 1981; Bhardwaj and Haider, 2002; Capria et al., 2005, 2008; Bhardwaj and Raghuram, 2012). Our recent theoretical study (Bhardwaj and Raghuram, 2012) for these prompt emissions of atomic oxygen in comet C/1996 B2 Hyakutake showed that more than 90\% of the $\mathrm{O}\left({ }^{1} \mathrm{D}\right)$ is populated via photodissociative excitation of $\mathrm{H}_{2} \mathrm{O}$ and the rest through photodissociation of other oxygen bearing species, like $\mathrm{CO}_{2}$ and $\mathrm{CO}$. It also showed that quenching by $\mathrm{H}_{2} \mathrm{O}$ is the major loss mechanism of $\mathrm{O}\left({ }^{1} \mathrm{D}\right)$ up to cometocentric distances of $1000 \mathrm{~km}$, and above that distance radiative decay takes over. The study of Bhardwaj and Raghuram (2012) demonstrated that the $\mathrm{G} / \mathrm{R}$ ratio depends not only on the photochemistry involved in populating $\mathrm{O}\left({ }^{1} \mathrm{~S}\right)$ and $\mathrm{O}\left({ }^{1} \mathrm{D}\right)$ atoms in the cometary coma, but also on the projected area observed for the comet, which is a function of slit dimension used for observation and geocentric distance of the comet.

In the present study we applied our coupled chemistryemission model (Bhardwaj and Raghuram, 2012) to comet C/1995 O1 Hale-Bopp, which had an order of magnitude higher $\mathrm{H}_{2} \mathrm{O}$ production rate compared to that of comet Hyakutake, to evaluate the production and loss mechanisms of $\mathrm{O}\left({ }^{1} \mathrm{D}\right)$ and $\mathrm{O}\left({ }^{1} \mathrm{~S}\right)$ and generation of green and red-doublet emissions. 
Our aim in this paper is to study the photo-attenuation in comets having high $\mathrm{H}_{2} \mathrm{O}$ production rates and its implications on the photochemistry of metastable $\mathrm{O}\left({ }^{1} \mathrm{~S}\right)$ and $\mathrm{O}\left({ }^{1} \mathrm{D}\right)$ atoms. We compared our model calculated [OI] $6300 \AA$ emission surface brightness profile with the observation of Morgenthaler et al. (2001). We have shown that the photodissociation of $\mathrm{H}_{2} \mathrm{O}$ mainly controls the formation of $\mathrm{O}\left({ }^{1} \mathrm{D}\right)$ and subsequently determines the intensity of [OI] $6300 \AA$ emission. However, in the case of $[\mathrm{OI}] 5577 \AA$ emission, the photodissociation of both $\mathrm{H}_{2} \mathrm{O}$ and $\mathrm{CO}_{2}$ plays an important role in the formation of metastable $\mathrm{O}\left({ }^{1} \mathrm{~S}\right)$, with photodissociation of $\mathrm{CO}_{2}$ being the major production source of $\mathrm{O}\left({ }^{1} \mathrm{~S}\right)$ in the inner cometary coma. We suggest that in comets with significant $(\geq 5 \%) \mathrm{CO}_{2}$ relative abundance, the photodissociation of $\mathrm{CO}_{2}$ is more effective in populating $\mathrm{O}\left({ }^{1} \mathrm{~S}\right)$ than the photodissociation of $\mathrm{H}_{2} \mathrm{O}$. The model calculated $\mathrm{G} / \mathrm{R}$ ratio is consistent with the observed value of Zhang et al. (2001). Based on the model results, we suggest that the involvement of multiple species in the formation $\mathrm{O}\left({ }^{1} \mathrm{~S}\right)$ could be a reason for the width of the green line emission to be larger than the red-doublet emission lines observed in several comets by Cochran (2008).

\section{Model}

The details of the model and the chemistry are presented in our previous work (Bhardwaj and Raghuram, 2012). Here we present the input parameters that have been used in the model for the observed condition of comet Hale-Bopp on 10 March 1997 (solar radio flux F10.7 = 74.7 $\times 10^{-22} \mathrm{~J} \mathrm{~s}^{-1} \mathrm{~m}^{-2}$ $\mathrm{Hz}^{-1}$ ) when it was at a geocentric distance $(\Delta)$ of $1.32 \mathrm{AU}$ and a heliocentric distance $\left(r_{h}\right)$ of $0.93 \mathrm{AU}$. The photochemical reaction network and cross sections for photon and electron impact processes are same as used in the previous work and any changes made are mentioned. The degradation of solar EUV-generated photoelectrons is accounted by using Analytical Yield Spectrum (AYS) technique which is based on the Monte-Carlo method (Singhal and Bhardwaj, 1991; Bhardwaj and Singhal, 1993; Bhardwaj and Michael, 1999a,b; Bhardwaj and Jain, 2009). Details of the AYS approach and the method to calculate photoelectron flux and excitation rates are given in our earlier papers (Bhardwaj et al., 1990, 1996; Bhardwaj, 1999, 2003; Haider and Bhardwaj, 2005; Bhardwaj and Raghuram, 2011; Raghuram and Bhardwaj, 2012; Bhardwaj and Jain, 2012).

In our previous work (Bhardwaj and Raghuram, 2012) it has been shown that the contribution of several processes to the production of $\mathrm{O}\left({ }^{1} \mathrm{~S}\right)$ and $\mathrm{O}\left({ }^{1} \mathrm{D}\right)$ is small. Thus, only important production and destruction mechanisms of metastable $\mathrm{O}\left({ }^{1} \mathrm{~S}\right)$ and $\mathrm{O}\left({ }^{1} \mathrm{D}\right)$ are presented in Table 1 . The branching ratio of 0.81 is used for the production of $\mathrm{OH}$ in the photodissociation of $\mathrm{H}_{2} \mathrm{O}$ (cf. Huebner et al., 1992; Nee and Lee, 1984). The radius of the cometary nucleus is taken as $25 \mathrm{~km}$ (Weaver et al., 1997; Combi et al., 1999). Though a variety of O-bearing minor species (with relative abundances $\leq 1 \%$, Bockelée-Morvan et al., 2000) have been found in comet Hale-Bopp, the dominant species $\mathrm{H}_{2} \mathrm{O}, \mathrm{CO}_{2}$, and $\mathrm{CO}$ are only considered in our model calculations. The neutral density profiles of these parent species are calculated using Haser's formula.
Using ground-based observations of direct $\mathrm{H}_{2} \mathrm{O}$ infrared emissions during January to May 1997, Dello Russo et al. (2000) derived water production rates at different heliocentric distances and fitted as a function of $r_{h}$ as $\mathrm{Q}_{\mathrm{H}_{2} \mathrm{O}}=8.35 \pm$ $0.13 \times 10^{30}\left[r_{h}^{(-1.88 \pm 0.13)}\right]$ molecules $\mathrm{s}^{-1}$. We used this expression as a standard input in calculating $\mathrm{H}_{2} \mathrm{O}$ density profiles on different days. The $\mathrm{H}_{2} \mathrm{O}$ production rates in Hale-Bopp are also derived by observing the emissions from its dissociative products, like $\mathrm{OH}$ 18-cm emission, $\mathrm{OH}(0-0) 3080 \AA$ emission, [OI] $6300 \AA$ emission, and H Lyman- $\alpha$, over large projected distances (Weaver et al., 1997; Colom et al., 1999; Schleicher et al., 1997; Combi et al., 2000; Woods et al., 2000; Morgenthaler et al., 2001; Harris et al., 2002; Fink, 2009). These derived $\mathrm{H}_{2} \mathrm{O}$ production rates depend on the observational condition and also on the assumed model parameters. We have discussed the effect of $\mathrm{H}_{2} \mathrm{O}$ production rate on the calculated green and red-doublet emission intensities of atomic oxygen in the Section 4.2.2.

High resolution ground-based infrared spectroscopic observations are used to study the $\mathrm{CO}$ production rate in comet Hale-Bopp from June 1996 to September 1997 (DiSanti et al., 2001). The spatial distribution of CO in the coma of HaleBopp is assumed to have two distinct sources: nucleusoriginated, and extensively distributed in the cometary coma. During this observation period, the relative abundance of $\mathrm{CO}$ is found to be $\sim 25 \%$ of $\mathrm{H}_{2} \mathrm{O}$. DiSanti et al. (2001) fitted the observed $\mathrm{CO}$ production rate as a function of heliocentric distance near the perihelion as $\mathrm{Q}_{C O}=2.07 \times 10^{30} \mathrm{r}_{h}^{-1.66 \pm 0.22}$ molecules $\mathrm{s}^{-1}$, and above $1.5 \mathrm{AU}$ as $\mathrm{Q}_{C O}=1.06 \times 10^{30}$ $\mathrm{r}_{h}^{-1.76 \pm 0.26}$ molecules $\mathrm{s}^{-1}$. Since observations of [OI] 6300 $\AA$ emission are done when comet was at around $1 \mathrm{AU}$, we have used the former formulation to calculate the neutral CO density in our model. DiSanti et al. (2001) suggested that the increase in $\mathrm{CO}$ production rate below 1.5 $\mathrm{AU}$ is due to distributed sources prevailing in the cometary coma. Recent study of Bockelée-Morvan et al. (2010) showed that the infrared CO (1-0) rotational vibrational emission lines are optical thick in the cometary coma of Hale-Bopp. Based on the modelling studies of these emission lines they rejected the idea of extended source distribution of $\mathrm{CO}$ in comet Hale-Bopp. However, our model calculations show that the role of $\mathrm{CO}$ in determining green and red-doublet emission intensities is very small compared to other species, and hence the impact of distributed $\mathrm{CO}$ source is insignificant on these forbidden emission lines.

The $\mathrm{CO}_{2}$ has been detected in Hale-Bopp by Crovisier et al. (1997) in April 1996, when the comet was at heliocentric distance of 2.9 AU. Based on the infrared emissions between 2.5 to $5 \mu \mathrm{m}$, the derived $\mathrm{CO}_{2}$ production rate at $2.9 \mathrm{AU}$ was $1.3 \times$ $10^{28}$ molecules s ${ }^{-1}$, which corresponds to a relative abundance of $\sim 20 \%$ of $\mathrm{H}_{2} \mathrm{O}$. Assuming that the photodissociative excitation is the main production mechanism in populating the $\mathrm{CO}\left(\mathrm{a}^{3} \Pi\right)$ metastable state, the observed CO Cameron band $\left(\mathrm{a}^{3} \Pi \rightarrow \mathrm{X}^{1} \Sigma^{+}\right)$emission intensity has been used to estimate the abundance of $\mathrm{CO}_{2}$ in this comet by Weaver et al. (1997). The estimated $\mathrm{CO}_{2}$ abundance is more than $10 \%$ when the comet was beyond 2.7 AU. However, our model calculations on comets 103P/Hartley 2 (Bhardwaj and Raghuram, 2011) and 1P/Halley (Raghuram and Bhardwaj, 2012) have shown that 
Table 1: Major production and destruction processes of the $\mathrm{O}\left({ }^{1} \mathrm{~S}\right)$ and $\mathrm{O}\left({ }^{1} \mathrm{D}\right)$. Photorates are calculated using solar flux on 10 Apr 1997 (solar minimum period : solar radio flux F10.7 $=74.7 \times 10^{-22} \mathrm{~J} \mathrm{~s}^{-1} \mathrm{~m}^{-2} \mathrm{~Hz}^{-1}$.) and scaled to 0.92 AU heliocentric distance.

\begin{tabular}{|c|c|c|}
\hline Reaction & Rate $\left(\mathrm{cm}^{-3} \mathrm{~s}^{-1}\right.$ or s $\left.\mathrm{s}^{-1}\right)$ & Reference \\
\hline $\mathrm{H}_{2} \mathrm{O}+\mathrm{h} \nu \rightarrow \mathrm{O}\left({ }^{1} \mathrm{~S}\right)+\mathrm{H}_{2}$ & $3.78 \times 10^{-8}$ & This work \\
\hline $\mathrm{OH}+\mathrm{h} \nu \rightarrow \mathrm{O}\left({ }^{1} \mathrm{~S}\right)+\mathrm{H}$ & $6.71 \times 10^{-8}$ & Huebner et al. $(1992)^{\ddagger}$ \\
\hline $\mathrm{CO}_{2}+\mathrm{h} \nu \rightarrow \mathrm{O}\left({ }^{1} \mathrm{~S}\right)+\mathrm{CO}$ & $8.5 \times 10^{-7}$ & This work \\
\hline $\mathrm{CO}+\mathrm{h} \nu \rightarrow \mathrm{O}\left({ }^{1} \mathrm{~S}\right)+\mathrm{C}$ & $4.0 \times 10^{-8}$ & Huebner and Carpenter (1979) \\
\hline $\mathrm{H}_{2} \mathrm{O}^{+}+\mathrm{e}_{t h} \rightarrow \mathrm{O}\left({ }^{1} \mathrm{~S}\right)+$ others & $4.3 \times 10^{-7}\left(300 / \mathrm{T}_{e}\right)^{0.5} \times 0.045^{\dagger}$ & Rosén et al. (2000) \\
\hline $\mathrm{O}\left({ }^{1} \mathrm{~S}\right)+\mathrm{H}_{2} \mathrm{O} \rightarrow 2 \mathrm{OH}$ & $3 \times 10^{-10}$ & Zipf (1969) \\
\hline $\mathrm{O}\left({ }^{1} \mathrm{~S}\right) \longrightarrow \mathrm{O}\left({ }^{3} \mathrm{P}\right)+\mathrm{h} \nu_{2972 \AA}$ & 0.134 & Slanger et al. (2006) \\
\hline $\mathrm{O}\left({ }^{1} \mathrm{~S}\right) \longrightarrow \mathrm{O}\left({ }^{1} \mathrm{D}\right)+\mathrm{h} \nu_{5577 \AA}^{2972 A}$ & 1.26 & Wiese et al. (1996) \\
\hline $\mathrm{H}_{2} \mathrm{O}+\mathrm{h} \nu \rightarrow \mathrm{O}\left({ }^{1} \mathrm{D}\right)+{ }^{5} \mathrm{H}_{2}$ & $9.5 \times 10^{-7}$ & This work \\
\hline $\mathrm{OH}+\mathrm{h} \nu \rightarrow \mathrm{O}\left({ }^{1} \mathrm{D}\right)+\mathrm{H}$ & $7.01 \times 10^{-6}$ & Huebner et al. $(1992)^{\S}$ \\
\hline $\mathrm{CO}_{2}+\mathrm{h} \nu \rightarrow \mathrm{O}\left({ }^{1} \mathrm{D}\right)+\mathrm{CO}$ & $6.2 \times 10^{-7}$ & This work \\
\hline $\mathrm{CO}+\mathrm{h} \nu \rightarrow \mathrm{O}\left({ }^{1} \mathrm{D}\right)+\mathrm{C}$ & $6.0 \times 10^{-8}$ & This work \\
\hline $\mathrm{H}_{2} \mathrm{O}^{+}+\mathrm{e}_{t h} \rightarrow \mathrm{O}\left({ }^{1} \mathrm{D}\right)+$ others & $4.3 \times 10^{-7}\left(300 / \mathrm{T}_{e}\right)^{0.5} \times 0.045^{\dagger}$ & Rosén et al. (2000) \\
\hline $\mathrm{CO}^{+}+\mathrm{e}_{t h} \rightarrow \mathrm{O}\left({ }^{1} \mathrm{D}\right)+$ others & $5.0 \times 10^{-8} \times\left(300 / \mathrm{T}_{e}\right)^{0.46}$ & Mitchell (1990) \\
\hline $\mathrm{O}\left({ }^{1} \mathrm{D}\right)+\mathrm{H}_{2} \mathrm{O} \rightarrow 2 \mathrm{OH}$ & $2.1 \times 10^{-10}$ & Atkinson et al. (1997) \\
\hline $\mathrm{O}\left({ }^{1} \mathrm{D}\right) \longrightarrow \mathrm{O}\left({ }^{3} \mathrm{P}\right)+\mathrm{h} \nu$ & $6.44 \times 10^{-3}$ & Storey and Zeippen (2000) \\
\hline $\mathrm{O}\left({ }^{1} \mathrm{D}\right) \longrightarrow \mathrm{O}\left({ }^{3} \mathrm{P}\right)+\mathrm{h} \nu^{6300 A}$ & $2.15 \times 10^{-3}$ & Storey and Zeippen (2000) \\
\hline
\end{tabular}

${ }^{\dagger} 0.045$ is the assumed branching ratio for the formation of $\mathrm{O}\left({ }^{1} \mathrm{~S}\right)$ and $\mathrm{O}\left({ }^{1} \mathrm{D}\right)$ via dissociative recombination of $\mathrm{H}_{2} \mathrm{O}^{+}$ion $($see $\mathrm{Bhardwaj}$ and Raghuram, 2012). ${ }^{\ddagger}$ Huebner et al. (1992) calculated this rate using theoretical OH absorption cross section of van Dishoeck and Dalgarno (1984). ${ }^{\S}$ Huebner et al. (1992) calculated this rate based on experimentally determined OH absorption cross section of Nee and Lee (1984). $\mathrm{h} \nu$ : solar photon; $\mathrm{e}_{t h}$ : thermal electron; $\mathrm{T}_{e}$ : electron temperature.

photoelectron impact excitation is the main production mechanism of CO Cameron band emission and not the photodissociation of $\mathrm{CO}_{2}$. Assuming that the $\mathrm{CO}_{2} / \mathrm{CO}$ abundance ratio did not vary with heliocentric distance in this comet, BockeléeMorvan et al. (2004) suggested $6 \%$ relative abundance of $\mathrm{CO}_{2}$ when the comet was at $1 \mathrm{AU}$. We have taken $6 \% \mathrm{CO}_{2}$ relative abundance with respect to $\mathrm{H}_{2} \mathrm{O}$ in the model. However, we discuss the impact of $\mathrm{CO}_{2}$ abundance by varying its relative abundance on the calculated intensities of green and reddoublet emissions. The $\mathrm{OH}$ neutral density profile in comet Hale-Bopp is calculated by fitting Harris et al. (2002) observed OH (0-0) $3080 \AA$ resonant scattering emission along the projected distance with the Haser's two step formulation. The photodissociative excitation rates of $\mathrm{OH}$ producing $\mathrm{O}\left({ }^{1} \mathrm{~S}\right)$ and $\mathrm{O}\left({ }^{1} \mathrm{D}\right)$ are taken from Huebner et al. (1992) which were determined using theoretical (van Dishoeck and Dalgarno, 1984) and experimental (Nee and Lee, 1984) photoabsorption cross sections, respectively.

There is a clear evidence that in comet Hale-Bopp the expansion velocity of neutrals increases with increasing cometocentric distance (Colom et al., 1999; Biver et al., 1997; Harris et al., 2002). The sources involved in accelerating the neutral species across the cometary coma is discussed in several works (Colom et al., 1999; Combi et al., 1999; Harris et al., 2002; Combi, 2002). To incorporate the acceleration of these neutrals in our model we have taken the velocity profile calculated by Combi et al. (1999) at 1 AU and used as a input in the Haser's density distribution. We also verified the effect of expansion velocity on the calculated intensity of green and red-doublet emissions by varying its static value between 0.7 to $2.2 \mathrm{~km} \mathrm{~s}^{-1}$, which is discussed in Section 4.2.1.

The input solar flux is taken from SOLAR2000 (S2K) v.2.36 model of Tobiska (2004) and scaled accordingly to the heliocentric distance of the comet at the time of observation. The

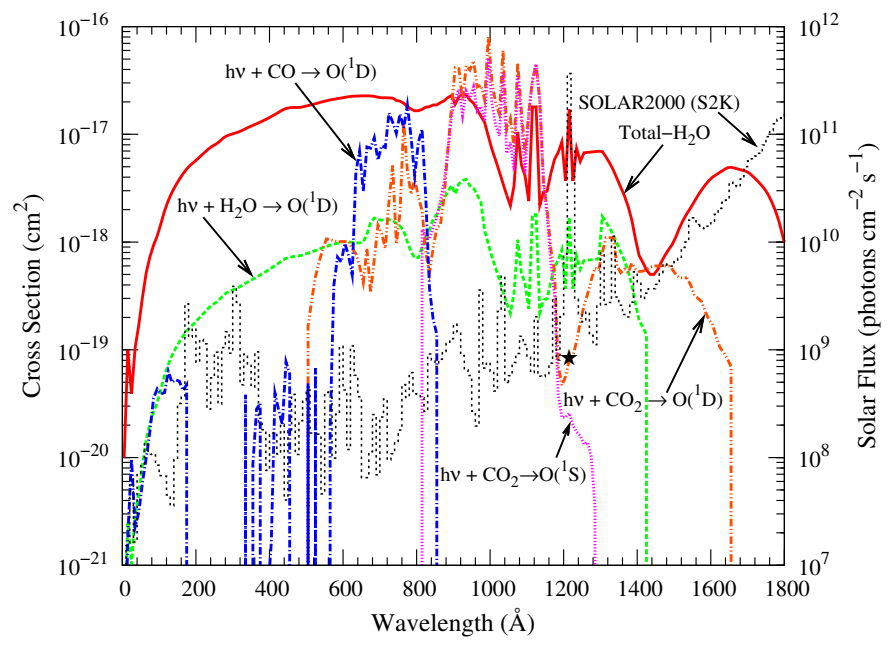

Figure 1: Photodissociative excitation cross sections for the production of $\mathrm{O}\left({ }^{1} \mathrm{D}\right)$ from $\mathrm{H}_{2} \mathrm{O}$ and $\mathrm{CO}$ are taken from Huebner et al. (1992). The photodissociation of $\mathrm{CO}_{2}$ for the production of $\mathrm{O}\left({ }^{1} \mathrm{D}\right)$ are taken from Jain and Bhardwaj (2012). The photodissociation cross section of $\mathrm{CO}_{2}$ producing $\mathrm{O}\left({ }^{1} \mathrm{~S}\right)$ is calculated using the yield suggested by Huestis et al. (2010) and total absorption cross section. $\star$ represents the cross section value for the production of $\mathrm{O}\left({ }^{1} \mathrm{~S}\right)$ from $\mathrm{H}_{2} \mathrm{O}$ at $1216 \AA$ assuming $0.5 \%$ yield. For comparison the total photoabsorption cross section of $\mathrm{H}_{2} \mathrm{O}$ taken from Huebner et al. (1992) is also shown. The solar flux taken from SOLAR2000 (S2K) model on 9 March 1997 (solar minimum condition; solar radio flux F10.7 = $\left.74.7 \times 10^{-22} \mathrm{~J} \mathrm{~s}^{-1} \mathrm{~m}^{-2} \mathrm{~Hz}^{-1}\right)$ is shown with scale on the right side $y$-axis. 


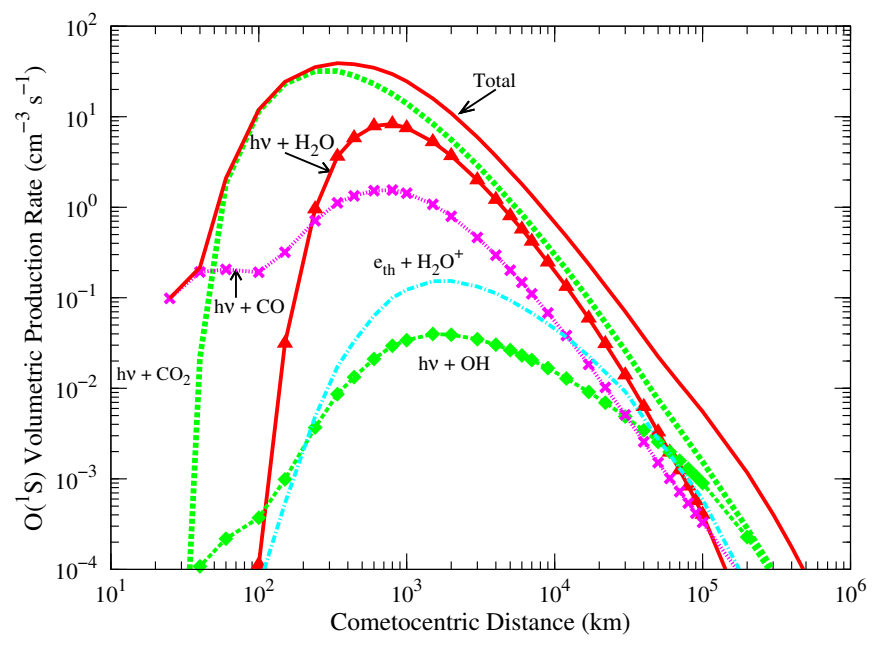

Figure 2: Calculated radial profiles for major production mechanisms of $\mathrm{O}\left({ }^{1} \mathrm{~S}\right)$ along with the total production profile for the abundances of $6 \% \mathrm{CO}_{2}$ and $24 \% \mathrm{CO}$ relative to $\mathrm{H}_{2} \mathrm{O}$ production rate of $8.3 \times 10^{30} \mathrm{~s}^{-1}$. $\mathrm{h} \nu$ : solar photon and $\mathrm{e}_{t h}$ : thermal electron

electron temperature profile required to calculate dissociative recombination rates is taken from Lovell et al. (2004). Bhardwaj and Raghuram (2012) have found that the yield of $\mathrm{O}\left({ }^{1} \mathrm{~S}\right)$ in the photodissociation of $\mathrm{H}_{2} \mathrm{O}$ at solar $\mathrm{H} \mathrm{Ly}-\alpha$ can not be more than $1 \%$. In the present study we have taken this yield value as $0.5 \%$. The impact of this assumption was discussed in our previous work (Bhardwaj and Raghuram, 2012). The photodissociative excitation cross section for $\mathrm{CO}_{2}$ producing $\mathrm{O}\left({ }^{1} \mathrm{D}\right)$ is taken from Jain and Bhardwaj (2012). The photodissociative excitation cross sections for the production of $\mathrm{O}\left({ }^{1} \mathrm{D}\right)$ and $\mathrm{O}\left({ }^{1} \mathrm{~S}\right)$ from $\mathrm{H}_{2} \mathrm{O}, \mathrm{CO}_{2}$, and $\mathrm{CO}$ used in the model are presented in Figure 1. The attenuation of solar radiation and solar UV-EUV generated photoelectrons in the cometary coma are described in our previous works (Bhardwaj et al., 1990; Bhardwaj, 1999, 2003; Bhardwaj and Haider, 1999; Raghuram and Bhardwaj, 2012).

\section{Results}

\subsection{Production and loss of $\mathrm{O}\left({ }^{1} \mathrm{~S}\right)$}

The calculated $\mathrm{O}\left({ }^{1} \mathrm{~S}\right)$ volumetric production rate profiles for major production processes are presented in Figure 2. The photodissociation of $\mathrm{CO}_{2}$ is the major production process of $\mathrm{O}\left({ }^{1} \mathrm{~S}\right)$. Above cometocentric distance of $1000 \mathrm{~km}$, the photodissociative excitation of $\mathrm{H}_{2} \mathrm{O}$ is also an equally important production source of $\mathrm{O}\left({ }^{1} \mathrm{~S}\right)$. Photodissociative excitation of $\mathrm{CO}$ is the next significant production mechanism in producing $\mathrm{O}\left({ }^{1} \mathrm{~S}\right)$. Since no cross section is reported in the literature for photodissociation of $\mathrm{CO}$ producing $\mathrm{O}\left({ }^{1} \mathrm{~S}\right)$, we have taken the photo-rate for this process from Huebner and Carpenter (1979) and assumed that the formation of $\mathrm{O}\left({ }^{1} \mathrm{~S}\right)$ is similar to $\mathrm{O}\left({ }^{1} \mathrm{D}\right)$. This assumption results in the calculated $\mathrm{O}\left({ }^{1} \mathrm{~S}\right)$ profile below $100 \mathrm{~km}$ similar to that of $\mathrm{O}\left({ }^{1} \mathrm{D}\right)$. However, this assumption does not make any significant impact on the calculated

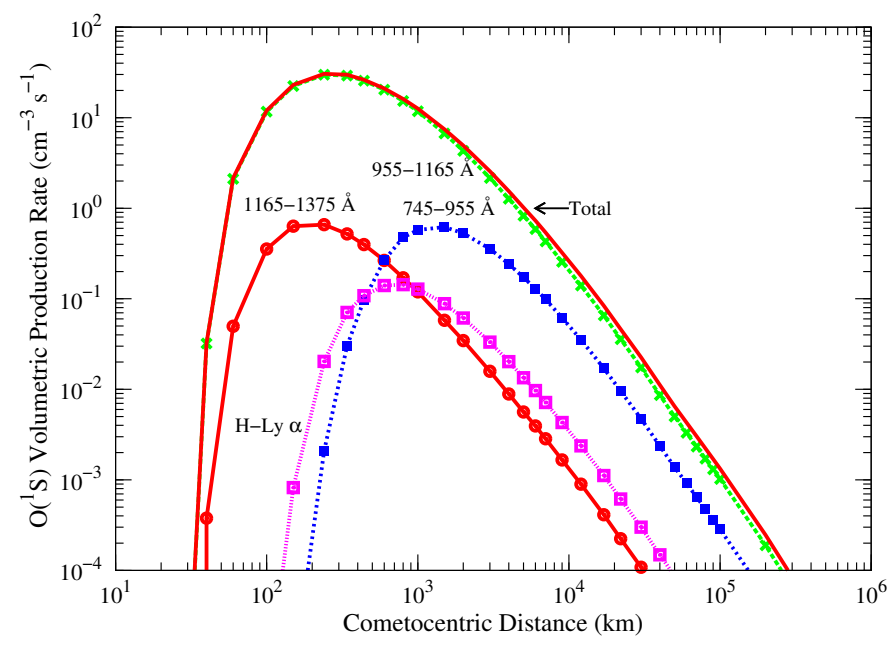

Figure 3: Calculated radial profiles for the photodissociation of $\mathrm{CO}_{2}$ producing $\mathrm{O}\left({ }^{1} \mathrm{~S}\right)$ at different wavelength bands for the abundances of $6 \% \mathrm{CO}_{2}$ and $24 \% \mathrm{CO}$ relative to $\mathrm{H}_{2} \mathrm{O}$ production rate of $8.3 \times 10^{30} \mathrm{~s}^{-1}$.

green line intensity, since photodissociation of $\mathrm{CO}_{2}$ and $\mathrm{H}_{2} \mathrm{O}$ can produce $\mathrm{O}\left({ }^{1} \mathrm{~S}\right)$ an order of magnitude higher than that of $\mathrm{CO}$ in the inner coma. Above $10^{4} \mathrm{~km}$, the contribution from dissociative recombination reactions of $\mathrm{H}_{2} \mathrm{O}^{+}$and $\mathrm{CO}^{+}$to the total $\mathrm{O}\left({ }^{1} \mathrm{~S}\right)$ production is significant. The photodissociation of $\mathrm{OH}$ is a minor source of $\mathrm{O}\left({ }^{1} \mathrm{~S}\right)$ below $10^{5} \mathrm{~km}$ radial distance.

The calculated $\mathrm{O}\left({ }^{1} \mathrm{~S}\right)$ volumetric production rate profiles for photodissociation of $\mathrm{CO}_{2}$ in the different wavelength bands are shown in Figure 3. The cross section for photodissociation of $\mathrm{CO}_{2}$ in the wavelength band $955-1165 \AA$ is higher by a few orders of magnitude compared to that at other wavelength regions (cf. Fig. 1). Moreover, in this wavelength band, the yield of $\mathrm{O}\left({ }^{1} \mathrm{~S}\right)$ in photodissociation of $\mathrm{CO}_{2}$ tends to unity (Slanger et al., 1977; Lawrence, 1972), while the total absorption cross section of $\mathrm{H}_{2} \mathrm{O}$ has a strong dip (cf. Fig. 1). Thus, solar photons in this wavelength band can dissociate $\mathrm{CO}_{2}$ and produce $\mathrm{O}\left({ }^{1} \mathrm{~S}\right)$ very efficiently. The photons in the wavelength bands 1165-1375 and 745-955 $\AA$ make a smaller (<10\%) contribution to the total $\mathrm{O}\left({ }^{1} \mathrm{~S}\right)$ production. The contribution of $1216 \AA$ solar photons to the $\mathrm{O}\left({ }^{1} \mathrm{~S}\right)$ formation is two orders of magnitude low because of the small absorption cross section of $\mathrm{CO}_{2}(\sim 8$ $\times 10^{-20} \mathrm{~cm}^{2}$ ).

The calculated volumetric destruction rate profiles of $\mathrm{O}\left({ }^{1} \mathrm{~S}\right)$ are presented in Figure 4. The collisional quenching of $\mathrm{O}\left({ }^{1} \mathrm{~S}\right)$ by $\mathrm{H}_{2} \mathrm{O}$ is the dominant loss process at cometocentric distances shorter than $300 \mathrm{~km}$. Above $1000 \mathrm{~km}$ the radiative decay via [OI] $5577 \AA$ line emission is the main loss process for the $\mathrm{O}\left({ }^{1} \mathrm{~S}\right)$ atom. The radiative decay via [OI] $2972 \AA$ emission is a minor loss process of $\mathrm{O}\left({ }^{1} \mathrm{~S}\right)$.

\subsection{Production and loss of $\mathrm{O}\left({ }^{1} \mathrm{D}\right)$}

The calculated volumetric production rate profiles of metastable $\mathrm{O}\left({ }^{1} \mathrm{D}\right)$ for different formation mechanisms are shown in Figure 5. Between 100 and $\sim 2 \times 10^{4} \mathrm{~km}$, most of the $\mathrm{O}\left({ }^{1} \mathrm{D}\right)(>90 \%)$ is produced via photodissociation of $\mathrm{H}_{2} \mathrm{O}$. 


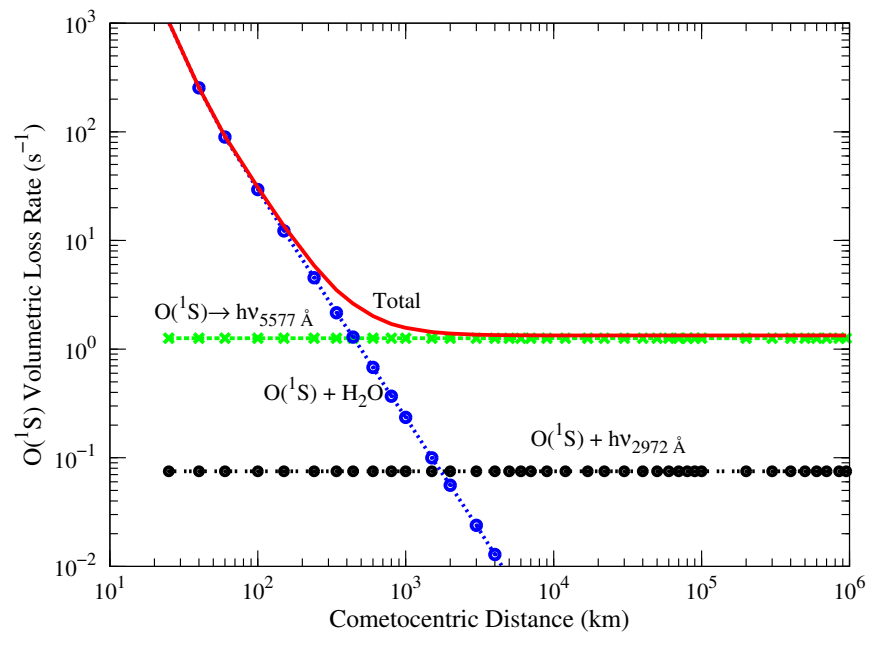

Figure 4: Calculated radial profiles for the major loss mechanisms of the $\mathrm{O}\left({ }^{1} \mathrm{~S}\right)$ atom for the abundances of $6 \% \mathrm{CO}_{2}$ and $24 \%$ CO relative to $\mathrm{H}_{2} \mathrm{O}$ production rate of $8.3 \times 10^{30} \mathrm{~s}^{-1}$.

However, below $100 \mathrm{~km}$, the photodissociation of $\mathrm{CO}_{2}$ is also an important source of $\mathrm{O}\left({ }^{1} \mathrm{D}\right)$. Between 200 and $2000 \mathrm{~km}$, the radiative decay of $\mathrm{O}\left({ }^{1} \mathrm{~S}\right)$ makes a minor contribution in the formation of $\mathrm{O}\left({ }^{1} \mathrm{D}\right)$. Above $10^{4} \mathrm{~km}$, the photodissociation of $\mathrm{OH}$ plays a significant role in the formation of $\mathrm{O}\left({ }^{1} \mathrm{D}\right)$. Even though the relative abundance of $\mathrm{CO}$ in Hale-Bopp is high $(\sim 25 \%)$, the photodissociation of $\mathrm{CO}$ is not a potential source mechanism of $\mathrm{O}\left({ }^{1} \mathrm{D}\right)$. The calculated $\mathrm{O}\left({ }^{1} \mathrm{D}\right)$ photodissociation rate profile for photodissociation of $\mathrm{CO}$ shows a double peak structure, which is explained later.

The wavelength-dependent production rates of $\mathrm{O}\left({ }^{1} \mathrm{D}\right)$ in the photodissociation of $\mathrm{H}_{2} \mathrm{O}$ are shown in Figure 6. The most intense line of solar UV spectrum, H Ly- $\alpha$ at $1216 \AA$, produces maximum $\mathrm{O}\left({ }^{1} \mathrm{D}\right)$ around $1000 \mathrm{~km}$, while solar photons in the wavelength regions $1165-1375$ and 1375-1575 $\AA$ are responsible for producing maximum $\mathrm{O}\left({ }^{1} \mathrm{D}\right)$ at shorter radial distances of 200 and $50 \mathrm{~km}$, respectively. Since the total absorption cross section of $\mathrm{H}_{2} \mathrm{O}$ in the $1165-1575 \AA$ wavelength region is small (cf. Fig. 1), these solar photons are able to penetrate deeper in the coma and mostly get attenuated at shorter cometocentric distances by dissociating $\mathrm{H}_{2} \mathrm{O}$. The $\mathrm{O}\left({ }^{1} \mathrm{D}\right)$ formation rate by solar photons at other wavelengths is smaller by more than an order of magnitude.

Similarly, the production rate of $\mathrm{O}\left({ }^{1} \mathrm{D}\right)$ due to photodissociation of $\mathrm{CO}_{2}$ calculated at different wavelength bands is shown in Figure 7. At radial distances $<100 \mathrm{~km}$, solar photons in 1375-1585 $\AA$ wavelength region is the main source for $\mathrm{O}\left({ }^{1} \mathrm{D}\right)$ formation. This is because the absorption cross section of $\mathrm{H}_{2} \mathrm{O}$ has a strong dip around $1400 \AA$ (cf. Fig. 1) and the average absorption cross section values of $\mathrm{H}_{2} \mathrm{O}$ and $\mathrm{CO}_{2}$ are nearly same in this wavelength region. Thus, solar photons in this wavelength band are able to reach the innermost coma and produce $\mathrm{O}\left({ }^{1} \mathrm{D}\right)$ by dissociating $\mathrm{CO}_{2}$. Since the cross section for production of $\mathrm{O}\left({ }^{1} \mathrm{D}\right)$ in photodissociation of $\mathrm{CO}_{2}$ peaks in the wavelength band 955-1165 $\AA$, the solar photons of this region leads the production of $\mathrm{O}\left({ }^{1} \mathrm{D}\right)$ above $500 \mathrm{~km}$.

The production rates of $\mathrm{O}\left({ }^{1} \mathrm{D}\right)$ via photodissociation of $\mathrm{CO}$

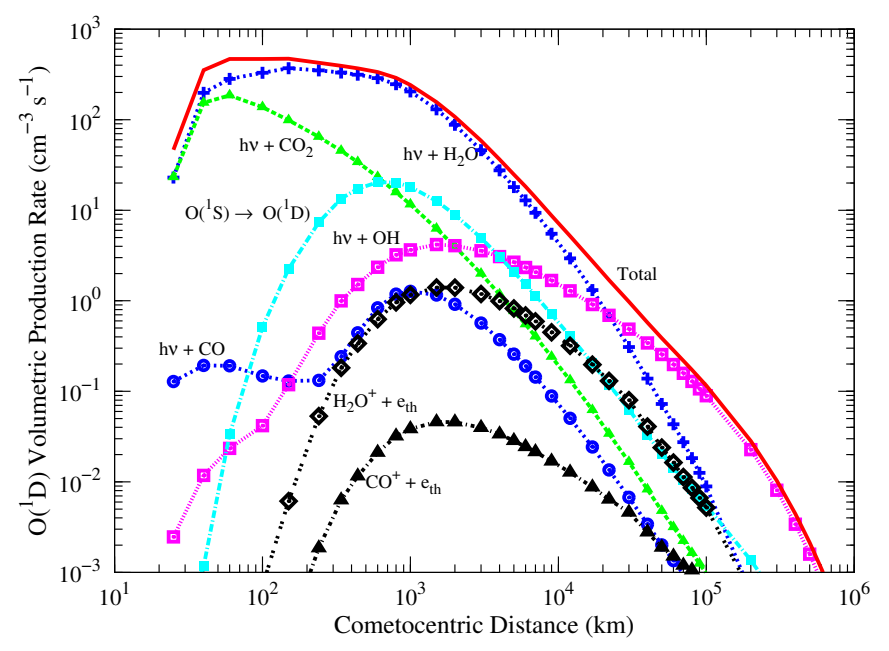

Figure 5: Calculated radial profiles for the major production mechanisms of $\mathrm{O}\left({ }^{1} \mathrm{D}\right)$ along with the total $\mathrm{O}\left({ }^{1} \mathrm{D}\right)$ production rate profile for the abundances of $6 \% \mathrm{CO}_{2}$ and $24 \% \mathrm{CO}$ relative to $\mathrm{H}_{2} \mathrm{O}$ production rate of $8.3 \times 10^{30} \mathrm{~s}^{-1}$. $\mathrm{h} \nu$ : solar photon.

in different wavelength bands are presented in Figure 8. The total absorption cross section of $\mathrm{H}_{2} \mathrm{O}$ is around two orders of magnitude smaller below $115 \AA$ than at other wavelengths, so these high energy photons can travel deeper into the cometary coma (even below $100 \mathrm{~km}$ ) almost unattenuated. Since the CO molecule offers a cross section (average $\sim 2 \times 10^{-20} \mathrm{~cm}^{2}$ ) to these photons it leads to the formation of $\mathrm{O}\left({ }^{1} \mathrm{D}\right)$ and $\mathrm{C}\left({ }^{1} \mathrm{D}\right)$ via photodissociation closer to the cometary nucleus. Between 100 and $500 \mathrm{~km}$, the solar photons in the wavelength region 115-325 $\AA$ produce maximum $\mathrm{O}\left({ }^{1} \mathrm{D}\right)$ atoms via photodissociation of $\mathrm{CO}$. The dissociative excitation cross section of $\mathrm{CO}$ is maximum in the wavelength region 535-955 $\AA$ (cf. Fig. 1), which results in the peak production of $\mathrm{O}\left({ }^{1} \mathrm{D}\right)$ via photodissociation of $\mathrm{CO}$ at $1000 \mathrm{~km}$. More details on the attenuation of solar flux in high water production rate comets are given in Bhardwaj (2003).

The model calculated volumetric loss rate profiles of $\mathrm{O}\left({ }^{1} \mathrm{D}\right)$ are presented in Figure 9. This figure depicts that the predominant destruction channel of $\mathrm{O}\left({ }^{1} \mathrm{D}\right)$ in the inner coma (below $3000 \mathrm{~km}$ ) of comet Hale-Bopp is quenching by $\mathrm{H}_{2} \mathrm{O}$, which results in the formation of two $\mathrm{OH}$ molecules. Above radial distance of $10^{4} \mathrm{~km}$, the radiative decay leading to the reddoublet emissions is the major loss for $\mathrm{O}\left({ }^{1} \mathrm{D}\right)$ atoms. Quenching by $\mathrm{CO}_{2}$ and $\mathrm{CO}$ are minor loss processes, about one order of magnitude smaller and hence is not shown.

The calculated density profiles of $\mathrm{O}\left({ }^{1} \mathrm{~S}\right), \mathrm{O}\left({ }^{1} \mathrm{D}\right)$, and $\mathrm{O}\left({ }^{3} \mathrm{P}\right)$ in comet Hale-Bopp along with parent species considered in our model are shown in Figure 10. The density of $\mathrm{O}\left({ }^{1} \mathrm{~S}\right)$ peaks around $500 \mathrm{~km}$, while the density profile of $\mathrm{O}\left({ }^{1} \mathrm{D}\right)$ shows a broad peak between 2000 and $5000 \mathrm{~km}$. The calculated number density profiles of $\mathrm{O}\left({ }^{1} \mathrm{D}\right)$ and $\mathrm{O}\left({ }^{1} \mathrm{~S}\right)$ without collisional quenching processes are also presented in this figure (with dashed lines). This calculation clearly shows that collisional quenching can significantly reduce the $\mathrm{O}\left({ }^{1} \mathrm{~S}\right)$ and $\mathrm{O}\left({ }^{1} \mathrm{D}\right)$ densities in the inner coma. The formation of $\mathrm{O}\left({ }^{3} \mathrm{P}\right)$ below 200 $\mathrm{km}$ is due to collisions between $\mathrm{OH}$ molecules. 


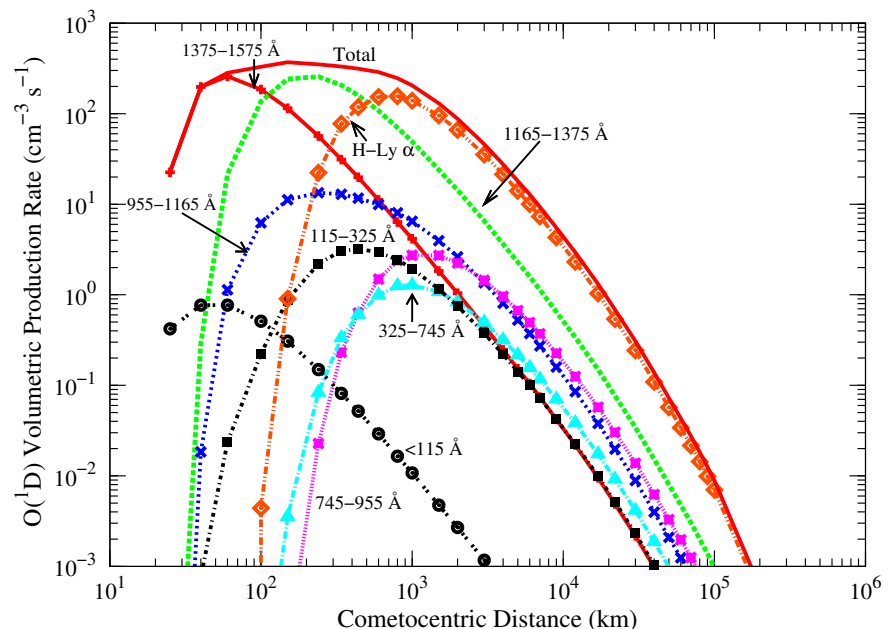

Figure 6: Calculated radial profiles for the photodissociation of $\mathrm{H}_{2} \mathrm{O}$ producing $\mathrm{O}\left({ }^{1} \mathrm{D}\right)$ at different wavelength bands for the abundances of $6 \% \mathrm{CO}_{2}$ and $24 \% \mathrm{CO}$ relative to $\mathrm{H}_{2} \mathrm{O}$ production rate of $8.3 \times 10^{30} \mathrm{~s}^{-1}$.

\subsection{Forbidden emissions of atomic oxygen: [OI] 5577, 2972, 6300, and $6364 \AA$}

The emission rates of [OI] 5577, 2972, 6300, and $6364 \AA$ are calculated by multiplying Einstein transition probabilities $\left(\mathrm{A}_{5577}=1.26 \mathrm{~s}^{-1}, \mathrm{~A}_{2972}=0.134 \mathrm{~s}^{-1}, \mathrm{~A}_{6300}=6.44 \times 10^{-3} \mathrm{~s}^{-1}\right.$, and $\left.\mathrm{A}_{6364}=2.17 \times 10^{-3} \mathrm{~s}^{-1}\right)$ with the densities of $\mathrm{O}\left({ }^{1} \mathrm{~S}\right)$ and $\mathrm{O}\left({ }^{1} \mathrm{D}\right)$ (see Bhardwaj and Raghuram (2012) for calculation details). The intensity of these line emissions along the line of sight is calculated by integrating the emission rates. The model calculated brightness profiles as a function of projected distance for these forbidden emissions along with the [OI] 6300 $\AA$ observations of Morgenthaler et al. (2001) made on 2 and 5 March 1997 using Hydra and WHAM instruments, respectively, are presented in Figure 11. To show the collisional quenching effect, we also presented the calculated forbidden emission line intensities (with dotted lines) in Figure 11, by considering only radiative decay as the loss process of $\mathrm{O}\left({ }^{1} \mathrm{~S}\right)$ and $\mathrm{O}\left({ }^{1} \mathrm{D}\right)$. The $[\mathrm{OI}] 2972 \AA$ emission profile is shown by taking branching ratio of $5577 / 2972$ as 10 as suggested by Slanger et al. (2006). The NIST recommended value for this ratio is 16 (Wiese et al., 1996).

The calculated percentage contributions of various processes involved in the production of metastable $\mathrm{O}\left({ }^{1} \mathrm{~S}\right)$ and $\mathrm{O}\left({ }^{1} \mathrm{D}\right)$ at different projected distances are presented in Table 2. For $6 \%$ relative abundance of $\mathrm{CO}_{2}$, photodissociation of $\mathrm{CO}_{2}$ is the major source of $\mathrm{O}\left({ }^{1} \mathrm{~S}\right)$ production rather than photodissociation of $\mathrm{H}_{2} \mathrm{O}$ (cf. Fig. 2). So we varied the $\mathrm{CO}_{2}$ relative abundance to study the change in the contribution of $\mathrm{CO}_{2}$ to the $\mathrm{O}\left({ }^{1} \mathrm{~S}\right)$ and $\mathrm{O}\left({ }^{1} \mathrm{D}\right)$ production. Calculations presented in Table 2 depict that, for a $6 \%$ relative abundance of $\mathrm{CO}_{2}$, below $10^{4} \mathrm{~km}$ projected distances, around 25 to $30 \%$ of $\mathrm{O}\left({ }^{1} \mathrm{~S}\right)$ production is via photodissociation of $\mathrm{H}_{2} \mathrm{O}$, while 40 to $60 \%$ production is through photodissociation of $\mathrm{CO}_{2}$. Though the relative abundance of $\mathrm{CO}$ in comet Hale-Bopp is high $(\sim 25 \%)$, the photodissociation of $\mathrm{CO}$ could contribute a maximum of

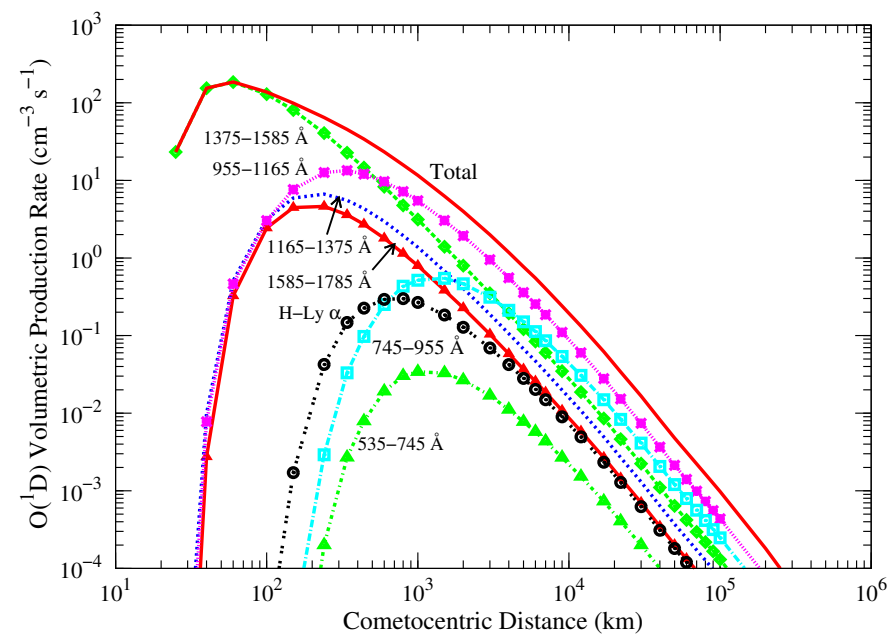

Figure 7: Calculated radial profiles for the photodissociation of $\mathrm{CO}_{2}$ producing $\mathrm{O}\left({ }^{1} \mathrm{D}\right)$ at different wavelength bands for the abundances of $6 \% \mathrm{CO}_{2}$ and $24 \% \mathrm{CO}$ relative to $\mathrm{H}_{2} \mathrm{O}$ production rate of $8.3 \times 10^{30} \mathrm{~s}^{-1}$.

$10 \%$ to the $\mathrm{O}\left({ }^{1} \mathrm{~S}\right)$ production. The dissociative recombination of $\mathrm{H}_{2} \mathrm{O}^{+}$and $\mathrm{CO}^{+}$together can contribute $10 \%$ to the production of $\mathrm{O}\left({ }^{1} \mathrm{~S}\right)$, whereas photodissociative excitation of $\mathrm{OH}$ is a minor $(<5 \%)$ source. At $10^{5} \mathrm{~km}$ projected distance, the photochemical reactions mentioned in Table 2 all together contributing $60 \%$ of $\mathrm{O}\left({ }^{1} \mathrm{~S}\right)$ and remaining is contributed by dissociative recombination of $\mathrm{O}$-bearing ions. When the abundance of $\mathrm{CO}_{2}$ is reduced to $3 \%$, below $10^{4} \mathrm{~km}$ projected distance, photodissociation of $\mathrm{H}_{2} \mathrm{O}(35$ to $40 \%)$ and $\mathrm{CO}_{2}$ (30 to $50 \%$ ) contribute almost equally to the production of $\mathrm{O}\left({ }^{1} \mathrm{~S}\right)$.

The major production process of $\mathrm{O}\left({ }^{1} \mathrm{D}\right)$ is the photodissociation of $\mathrm{H}_{2} \mathrm{O}$, whose contribution is 60 to $80 \%$ below $10^{4}$ $\mathrm{km}$ projected distance (cf. Table 2 ). Around $10^{4} \mathrm{~km}$ the photodissociation of $\mathrm{OH}$ is also a significant production source of $\mathrm{O}\left({ }^{1} \mathrm{D}\right)$ and contributes around $20 \%$; but, in the inner coma the contribution of this process is small $(<10 \%)$. Radiative decay of $\mathrm{O}\left({ }^{1} \mathrm{~S}\right)$ and electron recombination of $\mathrm{H}_{2} \mathrm{O}^{+}$contribute less than $10 \%$ each. At $10^{5} \mathrm{~km}$ projected distance, most $(75 \%)$ of $\mathrm{O}\left({ }^{1} \mathrm{D}\right)$ is produced by photodissociation of $\mathrm{OH}$ and remaining is contributed by other reactions. The change in the relative abundance of $\mathrm{CO}_{2}$ by a factor of 2 , from $6 \%$ to $3 \%$, does not affect the relative contributions of various sources of $\mathrm{O}\left({ }^{1} \mathrm{D}\right)$ below $10^{4} \mathrm{~km}$ projected distance.

Table 3: Calculated percentage contributions for the major production processes of green and red-doublet emissions in the total observed projected field of view $\left(2.4 \times 10^{5} \mathrm{~km}\right)$ on comet $\mathrm{C} / 1995 \mathrm{O} 1$ Hale-Bopp with varying relative abundance of $\mathrm{CO}_{2}$.

\begin{tabular}{cccccccc}
\hline $\mathrm{CO}_{2}(\%)$ & $\mathrm{h} \nu+\mathrm{H}_{2} \mathrm{O}$ & $\mathrm{h} \nu+\mathrm{OH}$ & $\mathrm{h} \nu+\mathrm{CO}_{2}$ & $\mathrm{e}^{-}+\mathrm{CO}_{2}^{+}$ & $\mathrm{e}^{-}+\mathrm{H}_{2} \mathrm{O}^{+}$ & $\mathrm{O}\left({ }^{1} \mathrm{~S}\right) \rightarrow \mathrm{O}\left({ }^{1} \mathrm{D}\right)$ & $\mathrm{h} \nu+\mathrm{CO}$ \\
\hline 6 & $23(48)^{\ddagger}$ & $4(35)$ & $41(3)$ & $8(0.5)$ & $7(5)$ & $(7)$ & $7(1)$ \\
3 & $32(50)$ & $6(36)$ & $30(2)$ & $5(0.5)$ & $10(8)$ & $(7)$ & $10(1)$ \\
1 & $42(50)$ & $8(37)$ & $13(0.5)$ & $2(0.5)$ & $13(8)$ & $(5)$ & $13(1)$ \\
\hline
\end{tabular}

${ }_{\ddagger}$ The values in parenthesis are the calculated percentage contributions for red-doublet emission. 
Table 2: Calculated percentage contributions for the major production processes of $\mathrm{O}\left({ }^{1} \mathrm{~S}\right)$ and $\mathrm{O}\left({ }^{1} \mathrm{D}\right)$ in comet Hale-Bopp with varying relative abundance of $\mathrm{CO}_{2}$ for $0.5 \% \mathrm{O}\left({ }^{1} \mathrm{~S}\right)$ yield.

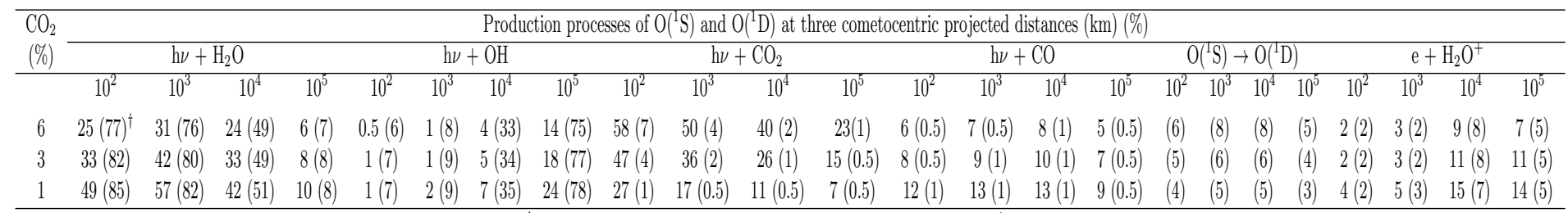

${ }^{\dagger}$ The values in parenthesis are for the $\mathrm{O}\left({ }^{1} \mathrm{D}\right)$.

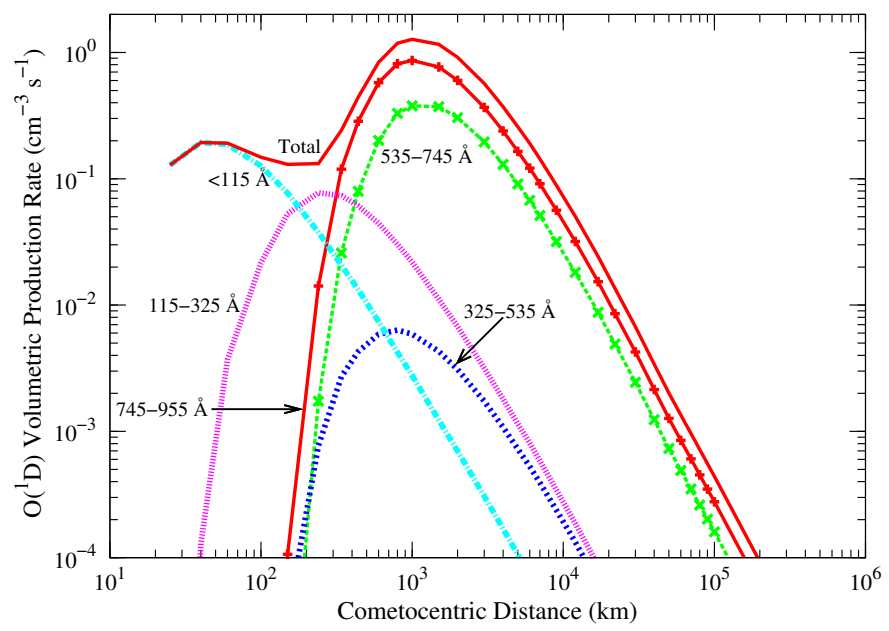

Figure 8: Calculated radial profiles for the photodissociation of $\mathrm{CO}$ producing $\mathrm{O}\left({ }^{1} \mathrm{D}\right)$ at different wavelength bands for the abundances of $6 \% \mathrm{CO}_{2}$ and $24 \% \mathrm{CO}$ relative to $\mathrm{H}_{2} \mathrm{O}$ production rate of $8.3 \times 10^{30} \mathrm{~s}^{-1}$.

For a $4^{\prime}$ circular aperture projected field of view $(\sim 2.4 \times$ $10^{5} \mathrm{~km}$ ) on comet Hale-Bopp, which is similar to the $50 \mathrm{~mm}$ Fabry-Pérot spectrometer observations of Morgenthaler et al. (2001), the calculated percentage contribution of major production processes for the green and red-doublet emissions, for different relative abundances of $\mathrm{CO}_{2}$, are presented in Table 3 . These calculations clearly suggest that in a comet which has been observed over a large projected area, the photodissociation of $\mathrm{H}_{2} \mathrm{O}$ and $\mathrm{OH}$ mainly $(\sim 80 \%)$ controls the [OI] 6300 $\AA$ emission, while the radiative decay of $\mathrm{O}\left({ }^{1} \mathrm{~S}\right)$ contributes a maximum value of $10 \%$ to the total red-doublet intensity. With $6 \%$ relative abundance of $\mathrm{CO}_{2}$, the [OI] $5577 \AA$ line emission observed in the coma is largely $(\sim 40 \%)$ contributed by photodissociation of $\mathrm{CO}_{2}$, and photodissociation of $\mathrm{H}_{2} \mathrm{O}$ is the next significant $(\sim 25 \%)$ production process. The other production processes, like dissociative recombination of ions, photodissociation of $\mathrm{CO}, \mathrm{OH}$, etc, together contribute less than $30 \%$ to the [OI] $5577 \AA$ intensity. When the $\mathrm{CO}_{2}$ abundance is reduced to $3 \%$, both photodissociation of $\mathrm{H}_{2} \mathrm{O}$ and $\mathrm{CO}_{2}$ are contributing equally $(\sim 30 \%)$ to the green line emission intensity. In all these cases, in spite of $\mathrm{CO}$ relative abundance being high $(\sim 25 \%)$ in comet Hale-Bopp, the photodissociation

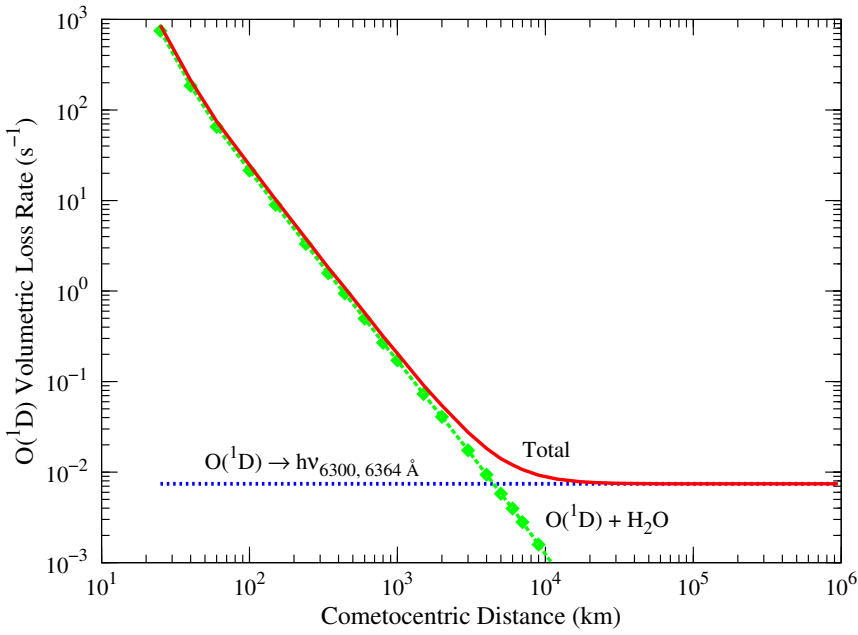

Figure 9: Calculated radial profiles for major loss mechanisms of the $\mathrm{O}\left({ }^{1} \mathrm{D}\right)$ atom for the abundances of $6 \% \mathrm{CO}_{2}$ and $24 \%$ $\mathrm{CO}$ relative to $\mathrm{H}_{2} \mathrm{O}$ production rate of $8.3 \times 10^{30} \mathrm{~s}^{-1}$.

of CO could contribute a maximum value of $10 \%$.

\subsection{Green to Red-doublet intensity ratio}

In comets, the parent species of these atomic oxygen emission lines are assessed using the ratio of intensity of the green line to the sum of intensities of the red-doublet, which can calculated as

$$
\frac{I_{5577}}{I_{6300}+I_{6364}}=\frac{\tau_{\text {green }}^{-1} \alpha_{\text {green }} N_{\text {green }} \beta_{\text {green }}}{\tau_{\text {red }}^{-1} \alpha_{\text {red }} N_{\text {red }}\left(\beta_{6300+6364}\right)}
$$

where $\tau$ is the lifetime of excited species in seconds $\left(\tau\left[\mathrm{O}\left({ }^{1} \mathrm{D}\right)\right]\right.$ $\approx 110 \mathrm{~s}$ and $\left.\tau\left[\mathrm{O}\left({ }^{1} \mathrm{~S}\right)\right] \approx 0.7 \mathrm{~s}\right), \alpha$ is the yield of photodissociation (Huebner et al., 1992), $\beta$ is the branching ratio $\left(\beta_{6300}\right.$ $=0.75, \beta_{6364}=0.25, \beta_{5577}=0.90$, and $\beta_{2972}=0.10$ (Wiese et al., 1996; Slanger et al., 2011; Festou and Feldman, 1981) of the transition, and $\mathrm{N}$ is the column density of cometary species in $\mathrm{cm}^{-2}$. Customarily, the observed $\mathrm{G} / \mathrm{R}$ ratio of 0.1 has been used to confirm the parent species of these oxygen lines as $\mathrm{H}_{2} \mathrm{O}$ in comets (Cochran, 1984, 2008; Morrison et al., 1997; Zhang et al., 2001; Cochran and Cochran, 2001; Furusho et al., 2006; Capria et al., 2005, 2008, 2010). However, since no experimental cross section or yield for the production of $\mathrm{O}\left({ }^{1} \mathrm{~S}\right)$ from $\mathrm{H}_{2} \mathrm{O}$ is available in the literature, this ratio has been questioned by Huestis and Slanger (2006). In our pre- 


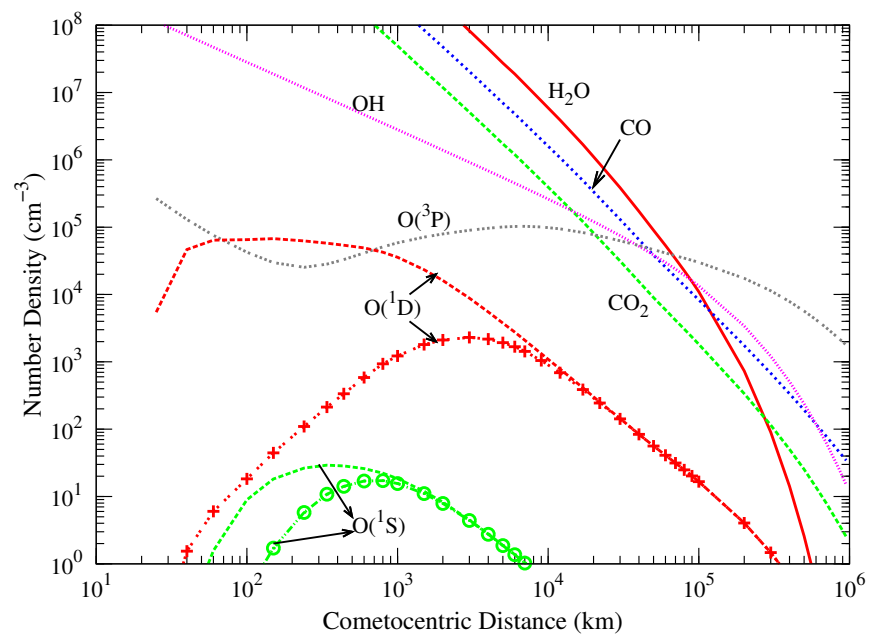

Figure 10: Calculated number density profiles of $\mathrm{O}\left({ }^{1} \mathrm{~S}\right)$, $\mathrm{O}\left({ }^{1} \mathrm{D}\right), \mathrm{O}\left({ }^{3} \mathrm{P}\right)$, and $\mathrm{OH}$, along with those of $\mathrm{H}_{2} \mathrm{O}, \mathrm{CO}$, and $\mathrm{CO}_{2}$. The calculations are done for the abundances of $6 \%$ $\mathrm{CO}_{2}$ and $24 \% \mathrm{CO}$ relative to $\mathrm{H}_{2} \mathrm{O}$ production rate of $8.3 \times$ $10^{30} \mathrm{~s}^{-1}$. The dashed lines of $\mathrm{O}\left({ }^{1} \mathrm{~S}\right)$ and $\mathrm{O}\left({ }^{1} \mathrm{D}\right)$ are the calculated densities without accounting the collisional quenching processes.

vious work (Bhardwaj and Raghuram, 2012), by fitting the observed green line emission intensity in comet C/1996 B2 Hyakutake, we suggested that the yield for photo-production rate of $\mathrm{O}\left({ }^{1} \mathrm{~S}\right)$ from $\mathrm{H}_{2} \mathrm{O}$ at solar $\mathrm{H} \mathrm{Ly}-\alpha$ can not be more than $1 \%$. Our previous model calculation also demonstrated that the determined $\mathrm{G} / \mathrm{R}$ ratio depends on the projected area observed over the comet.

We calculated the $\mathrm{G} / \mathrm{R}$ ratio profiles on comet Hale-Bopp on 26 March 1997 by varying $\mathrm{CO}_{2}$ relative abundance from 6 to 3 to $1 \%$ which are presented in Figure 12 . For comparison, the $\mathrm{G} / \mathrm{R}$ ratio profile calculated on comet Hyakutake (Bhardwaj and Raghuram, 2012) is also plotted in Figure 12. In comet Hyakutake the $\mathrm{G} / \mathrm{R}$ ratio is constant up to $100 \mathrm{~km}$ projected distance, while in the case of comet Hale-Bopp it is constant even up to $1000 \mathrm{~km}$. The flatness of the $\mathrm{G} / \mathrm{R}$ ratio depends on the quenching rate of metastable $\mathrm{O}\left({ }^{1} \mathrm{~S}\right)$ and $\mathrm{O}\left({ }^{1} \mathrm{D}\right)$ by $\mathrm{H}_{2} \mathrm{O}$ which is a function of water production rate of the comet. Thus, in comets where $\mathrm{H}_{2} \mathrm{O}$ production rate is still larger than that of Hale-Bopp, the $\mathrm{G} / \mathrm{R}$ ratio would be constant up to projected distances larger than $10^{3} \mathrm{~km}$.

\subsection{Radiative efficiencies of $\mathrm{O}\left({ }^{1} \mathrm{~S}\right)$ and $\mathrm{O}\left({ }^{1} \mathrm{D}\right)$ atoms}

The number density of $\mathrm{O}\left({ }^{1} \mathrm{~S}\right)$ and $\mathrm{O}\left({ }^{1} \mathrm{D}\right)$ in the cometary coma is controlled by various production and loss processes at that radial distance. To understand the region of maximum emission of green and red-doublet lines in the coma we calculated the radiative efficiency profiles of $\mathrm{O}\left({ }^{1} \mathrm{~S}\right)$ and $\mathrm{O}\left({ }^{1} \mathrm{D}\right)$ in comets Hale-Bopp and Hyakutake by calculating the ratio of emission rate to total production rate of respective species. The calculated radiative efficiency profiles of $\mathrm{O}\left({ }^{1} \mathrm{~S}\right)$ and $\mathrm{O}\left({ }^{1} \mathrm{D}\right)$ are presented in Figure 13 with solid and dotted line for comets

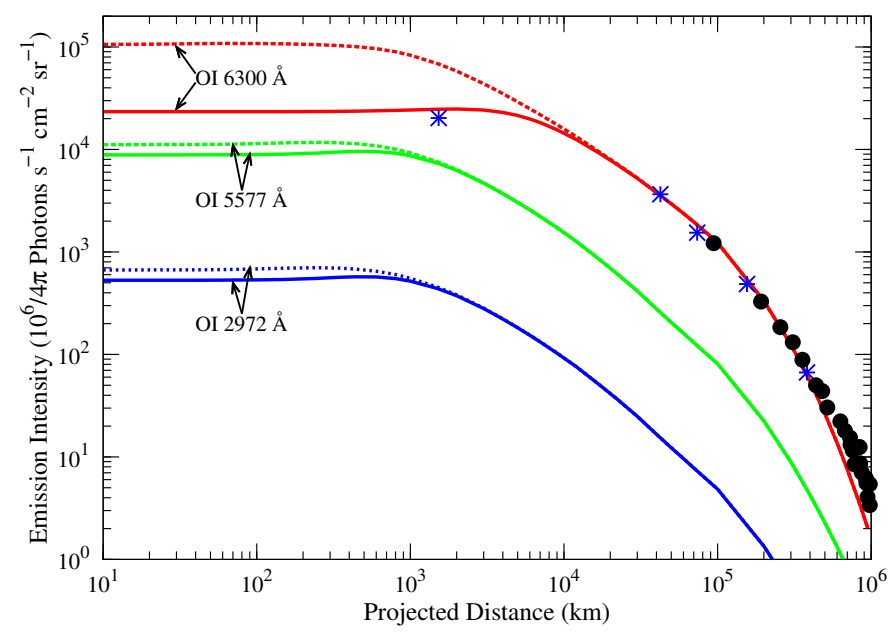

Figure 11: Calculated [OI] 6300, 5577, and $2972 \AA$ A line brightness profiles as a function of the projected distances for the abundances of $6 \% \mathrm{CO}_{2}$ and $24 \% \mathrm{CO}$ relative to $\mathrm{H}_{2} \mathrm{O}$ production rate of $8.3 \times 10^{30} \mathrm{~s}^{-1}$. For comparison the observed intensities of $6300 \AA$ line emission by Morgenthaler et al. (2001) using Hydra (stars) and WHAM (filled circles) instruments on 1997 March $2\left(r_{h}=1.05 \mathrm{AU}\right.$ and $\left.\Delta=1.46 \mathrm{AU}\right)$ and $5\left(r_{h}\right.$ $=1.03 \mathrm{AU}$ and $\Delta=1.42 \mathrm{AU})$, respectively, are also shown. During the observation the field of view of Hydra and WHAM instruments are $1^{\circ}$ and $45^{\prime}$, respectively (Morgenthaler et al., 2001). Dotted lines are the calculated intensities when collisional quenching is not accounted.

Hale-Bopp and Hyakutake, respectively. This figure depicts that in comet Hale-Bopp all the $\mathrm{O}\left({ }^{1} \mathrm{~S}\right)$ atoms produced above $1000 \mathrm{~km}$ radial distance emit $5577 \AA$ (or $2972 \AA$ ) photons, while for $\mathrm{O}\left({ }^{1} \mathrm{D}\right)$ the radiative efficiency is unity above $10^{4} \mathrm{~km}$. Since the lifetime of $\mathrm{O}\left({ }^{1} \mathrm{D}\right)$ is higher by two orders of magnitude than that of $\mathrm{O}\left({ }^{1} \mathrm{~S}\right)$, most of the produced $\mathrm{O}\left({ }^{1} \mathrm{D}\right)$ in the inner coma get quenched by other cometary species (mainly by $\mathrm{H}_{2} \mathrm{O}$ ) without emitting photons at wavelengths 6300 and $6364 \AA$. But in case of comet Hyakutake the radiative efficiency of $\mathrm{O}\left({ }^{1} \mathrm{~S}\right)$ and $\mathrm{O}\left({ }^{1} \mathrm{D}\right)$ is unity above 100 and $1000 \mathrm{~km}$, respectively. This calculation shows that in comets most of the green and red-doublet emissions are produced above the collisional-dominated region where the radiative decay is the dominant loss process for $\mathrm{O}\left({ }^{1} \mathrm{~S}\right)$ and $\mathrm{O}\left({ }^{1} \mathrm{D}\right)$ atoms.

\subsection{Excess velocities of $\mathrm{O}\left({ }^{1} \mathrm{~S}\right)$ and $\mathrm{O}\left({ }^{1} \mathrm{D}\right)$}

Solar photons having energy more than the dissociation threshold of cometary species impart the additional energy to the kinetic motions of daughter products. The mean excess energy released in the $i$ th dissociation process at a radial distance $r$ can be determined as

$$
E_{i}(r)=\frac{\int_{0}^{\lambda_{t h}} h c\left(\frac{1}{\lambda}-\frac{1}{\lambda_{t h}}\right) \sigma(\lambda) \phi(\lambda, r) e^{-\tau(\lambda, r)} d \lambda}{\int_{0}^{\lambda_{t h}} \sigma(\lambda) \phi(\lambda, r) e^{-\tau(\lambda, r)} d \lambda}
$$




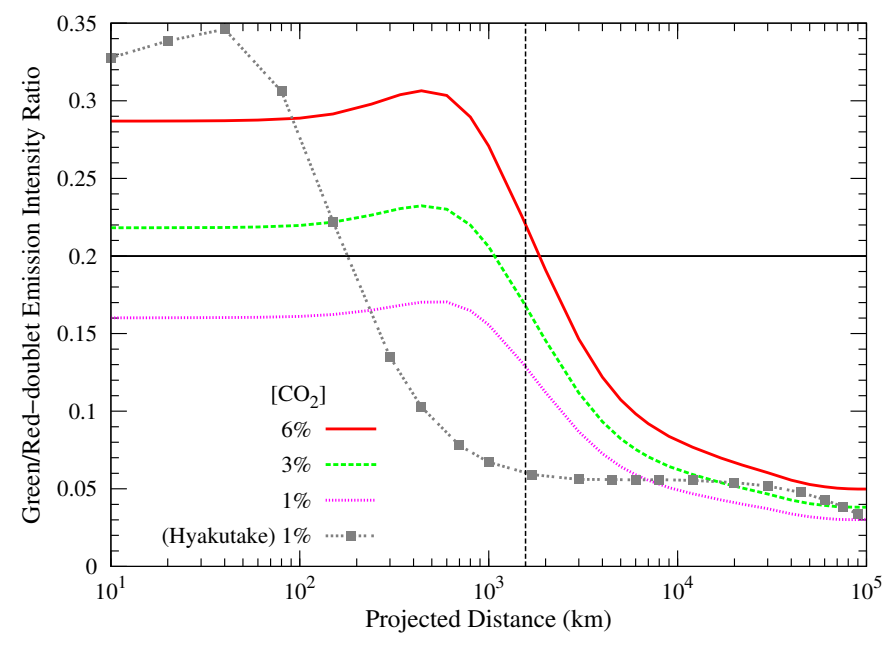

Figure 12: Calculated green to red-doublet intensity ratio along projected distances for different $\mathrm{CO}_{2}$ relative abundance $\left[\mathrm{CO}_{2}\right]$ and with $0.5 \%$ yield for $\mathrm{O}\left({ }^{1} \mathrm{~S}\right)$ production in the photodissociation of $\mathrm{H}_{2} \mathrm{O}$. Zhang et al. (2001) observed average green to red-doublet intensity ratio was 0.2 for the slit projected size of $522 \times 1566 \mathrm{~km}$ over comet Hale-Bopp on 28 March 1997, which is shown with a horizontal line. The vertical dotted line represents $1566 \mathrm{~km}$ projected distance on the cometary coma. For comparison the calculated $\mathrm{G} / \mathrm{R}$ ratio profile with $1 \% \mathrm{CO}_{2}$ and $0.5 \%$ yield in comet $\mathrm{C} / 1996$ B2 Hyakutake is also shown.

where $\lambda$ is the wavelength of solar photon, $\lambda_{t h}$ is the threshold wavelength for the dissociation process, $h$ is Planck's constant, and $c$ is the velocity of light. $\sigma(\lambda)$ is the dissociation cross section of the cometary species at wavelength $\lambda . \phi(\lambda, r)$ and $\tau(\lambda, r)$ are the solar flux and the optical depth of the medium for the photon of the wavelength $\lambda$ at a radial distance $r$, respectively.

Our model calculated mean excess energy profiles for the photodissociation of $\mathrm{H}_{2} \mathrm{O}, \mathrm{CO}_{2}$, and $\mathrm{CO}$ forming $\mathrm{O}\left({ }^{1} \mathrm{~S}\right)$ and $\mathrm{O}\left({ }^{1} \mathrm{D}\right)$ are presented in Figure 14 with solid and dotted lines for comets Hale-Bopp and Hyakutake, respectively. Above $3000 \mathrm{~km}$ radial distance, the calculated excess energies in different photodissociation processes in both comets show a constant profile, because the optical depth in this region for photons of different wavelengths is very small. These values are in agreement with the calculations of Huebner et al. (1992). However, at shorter radial distances the neutral density is higher and hence the wavelength dependent photodissociation is significant which causes different excess energy values.

In comet Hale-Bopp the calculated mean excess energy in photodissociation of $\mathrm{H}_{2} \mathrm{O}$ producing $\mathrm{O}\left({ }^{1} \mathrm{D}\right)$ shows a highest value of $5.6 \mathrm{eV}$ at the surface of the nucleus and decreases to a minimum value of $0.7 \mathrm{eV}$ at $50 \mathrm{~km}$. Above $50 \mathrm{~km}$ the mean excess energy increases and becomes constant $(2.12 \mathrm{eV})$ above $3000 \mathrm{~km}$. This is because of the formation of $\mathrm{O}\left({ }^{1} \mathrm{D}\right)$ via the photodissociation of $\mathrm{H}_{2} \mathrm{O}$ is associated with the photons of different energies and it also varies with radial distance as shown in Figure 6. At a given radial distance the mean excess energy released in the photodissociation process is determined by

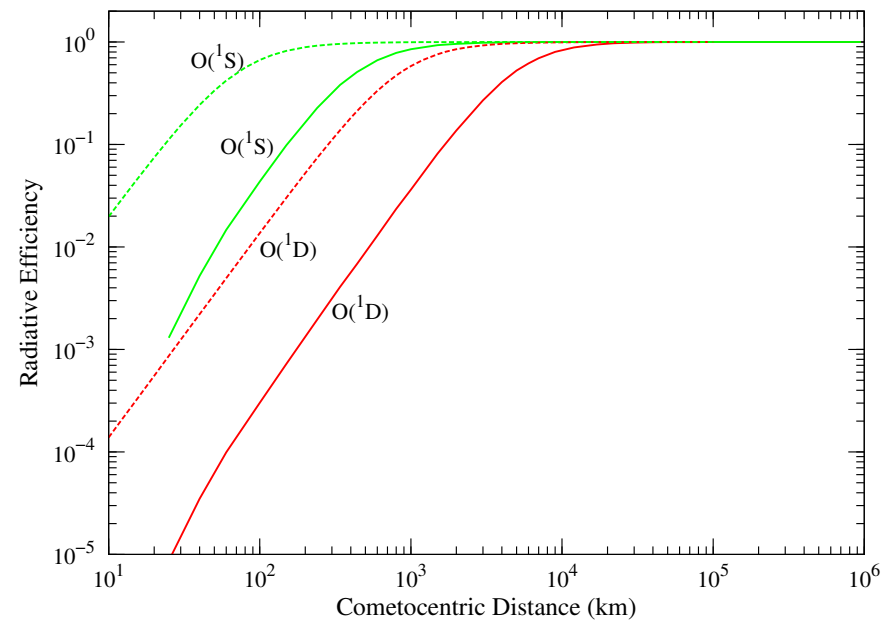

Figure 13: The calculated radiative efficiency profiles of $\mathrm{O}\left({ }^{1} \mathrm{~S}\right)$ and $\mathrm{O}\left({ }^{1} \mathrm{D}\right)$ on comets Hale-Bopp (solid lines) and Hyakutake (dashed lines). Radiative efficiency is the ratio of emission rate to the production rate.

the mean of energies of different solar photons involved. The threshold energy for production of $\mathrm{O}\left({ }^{1} \mathrm{D}\right)$ by dissociating $\mathrm{H}_{2} \mathrm{O}$ is $7 \mathrm{eV}$. Very close to the cometary nucleus $(<50 \mathrm{~km})$, photons of wavelength smaller than $115 \AA$ and in the wavelength band $1375-1575 \AA$ A determines the formation of $\mathrm{O}\left({ }^{1} \mathrm{D}\right)$ (cf. Fig. 6). At this distance, most of $\mathrm{O}\left({ }^{1} \mathrm{D}\right)$ is produced by the photons of low energy $(7-9 \mathrm{eV})$ in the wavelength band 1375-1575 $\AA$, and a small amount of $\mathrm{O}\left({ }^{1} \mathrm{D}\right)$ is produced by very high energy $(>100 \mathrm{eV})$ photons which results in the mean excess energy of about $2-5 \mathrm{eV}$. But around $50 \mathrm{~km}$, the majority of $\mathrm{O}\left({ }^{1} \mathrm{D}\right)$ production is determined by the photons of low energy 7 to 12 $\mathrm{eV}$ (955-1575 $\AA$ wavelength band) and the contribution from photons of wavelength below $115 \AA$ is very small. This causes the minimum value of mean excess energy $0.7 \mathrm{eV}$ at this radial distance.

Between 50 and $300 \mathrm{~km}$, the increase in the excess energy is due to the production of $\mathrm{O}\left({ }^{1} \mathrm{D}\right)$ atoms by photons of wavelength bands 115-325, 955-1575 A, and solar H Ly- $\alpha$. Though high energy photons $(115-325 \AA)$ are also involved in this region, the intense solar photon flux at H Ly- $\alpha(1216 \AA)$ governs the majority of $\mathrm{O}\left({ }^{1} \mathrm{D}\right)$ production and subsequently determines the mean excess energy. The solar H Ly- $\alpha$ photons can provide the maximum excess energy of $3 \mathrm{eV}$ in the photodissociation of $\mathrm{H}_{2} \mathrm{O}$. Above $1000 \mathrm{~km}$ more than $90 \%$ of the $\mathrm{O}\left({ }^{1} \mathrm{D}\right)$ production is controlled by photons at $1216 \AA$ wavelength and the remaining from other wavelength bands (cf. Fig. 6), which results a constant value of mean excess energy of $2.12 \mathrm{eV}$.

Similarly, the mean excess energy calculated in the photodissociation of $\mathrm{CO}_{2}$ producing $\mathrm{O}\left({ }^{1} \mathrm{D}\right)$ can be explained based on the wavelength dependent photon attenuated profiles presented in Figure 7. The threshold energy for the $\mathrm{O}\left({ }^{1} \mathrm{D}\right)$ production in photodissociation of $\mathrm{CO}_{2}$ is $7 \mathrm{eV}$ and for $\mathrm{O}\left({ }^{1} \mathrm{~S}\right)$ it is $9 \mathrm{eV}$. At radial distances less than $100 \mathrm{~km}$, the production of $\mathrm{O}\left({ }^{1} \mathrm{D}\right)$ in photodissociation of $\mathrm{CO}_{2}$ is determined by the photons of low energy (average $8 \mathrm{eV}$ ) in the wavelength bands 1375-1785 $\AA$ and 955-1165 $\AA$, which results in low mean excess energy of $\sim 1 \mathrm{eV}$. Above $100 \mathrm{~km}$, photons of different energies 


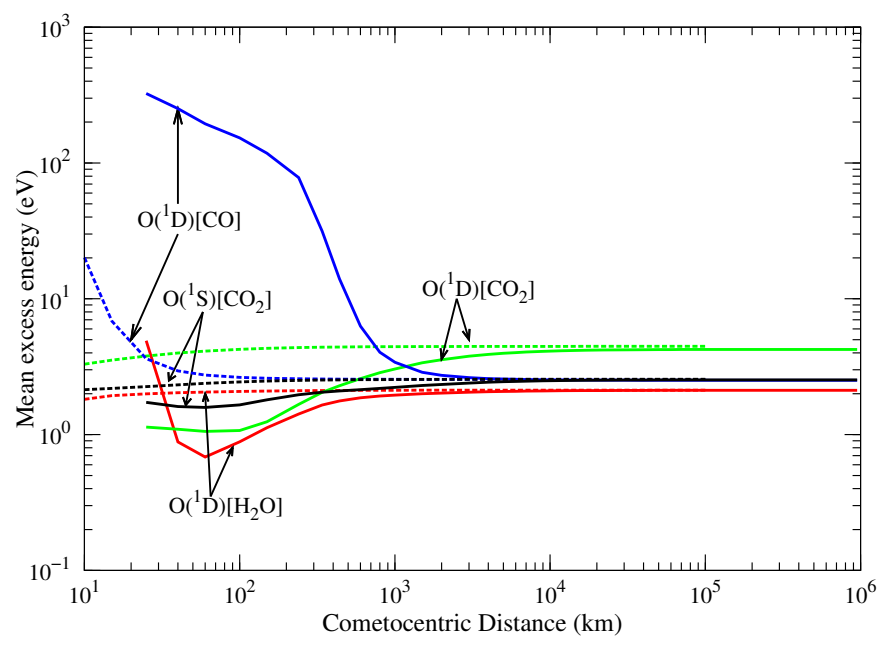

Figure 14: Calculated excess energy profiles of $\mathrm{O}\left({ }^{1} \mathrm{D}\right)$ in photodissociation of $\mathrm{H}_{2} \mathrm{O}, \mathrm{CO}$, and $\mathrm{CO}_{2}$ and that of $\mathrm{O}\left({ }^{1} \mathrm{~S}\right)$ in photodissociation of $\mathrm{CO}_{2}$ on comets Hale-Bopp (solid lines) and Hyakutake (dashed lines).

ranging from 7 to $16 \mathrm{eV}$ (cf. Fig. 7) causes the mean excess energy of $\sim 4 \mathrm{eV}$. The calculated mean excess energy profiles in the photodissociation of $\mathrm{CO}_{2}$ producing $\mathrm{O}\left({ }^{1} \mathrm{~S}\right)$ and $\mathrm{O}\left({ }^{1} \mathrm{D}\right)$ are not similar. This is because the $\mathrm{O}\left({ }^{1} \mathrm{~S}\right)$ production occurs via photodissociation of $\mathrm{CO}_{2}$ in the wavelength band of 800 to $1300 \AA$ (photons of $10-15 \mathrm{eV}$ ), whereas $\mathrm{O}\left({ }^{1} \mathrm{D}\right)$ can be produced by photons of wavelength less than $800 \AA$ (>15 eV) (cf. Fig. 1).

The threshold energy for the dissociation of CO producing $\mathrm{O}\left({ }^{1} \mathrm{D}\right)$ is $14.3 \mathrm{eV}$. Below $200 \mathrm{~km}$ the calculated maximum mean excess energy in the photodissociation of CO producing $\mathrm{O}\left({ }^{1} \mathrm{D}\right)$ is more than $100 \mathrm{eV}$. This is because the formation of $\mathrm{O}\left({ }^{1} \mathrm{D}\right)$ at these distances (cf. Fig. 8) is mainly determined by photons of wavelength less than $115 \AA$ (>110 eV) with some contribution from the wavelength band 115-325 $\AA$ (40-110 $\mathrm{eV})$. Above $500 \mathrm{~km}$, the formation of $\mathrm{O}\left({ }^{1} \mathrm{D}\right)$ is mainly due to solar photons in the wavelength band 535-955 $\AA(23-13 \mathrm{eV})$ which results in the maximum excess energy of $2.5 \mathrm{eV}$.

\section{Discussion}

The major difference between comets Hale-Bopp and Hyakutake is the $\mathrm{H}_{2} \mathrm{O}$ production rate, which is larger by a factor of 30 in the former. This difference in the $\mathrm{H}_{2} \mathrm{O}$ production rates result in a change in the photochemistry of $\mathrm{O}\left({ }^{1} \mathrm{~S}\right)$ and $\mathrm{O}\left({ }^{1} \mathrm{D}\right)$ in the cometary coma. Due to the dense coma of comet Hale-Bopp, the attenuation of solar UV-EUV photons on Hale-Bopp differs significantly from that in Hyakutake. Moreover, the $\mathrm{CO}_{2}$ abundance in comet Hyakutake is smaller $(<3 \%$ relative abundance) compared to that in HaleBopp ( $\sim 6 \%$ relative abundance). The high $\mathrm{H}_{2} \mathrm{O}$ production rate in comet Hale-Bopp results in a larger collisional coma (radius few $\times 10^{5} \mathrm{~km}$ ) which is comparable to the scale length $\left(\sim 8 \times 10^{4} \mathrm{~km}\right)$ of $\mathrm{H}_{2} \mathrm{O}$ molecule. In the low production rate comets the collisional zone is smaller and photochemistry significantly differs.
The photodissociation rates of $\mathrm{H}_{2} \mathrm{O}$ and $\mathrm{CO}_{2}$ for $\mathrm{O}\left({ }^{1} \mathrm{~S}\right)$ production differ by a factor of 20 (cf. Table 1). Hence, the major source of $\mathrm{O}\left({ }^{1} \mathrm{~S}\right)$ in the inner coma of comet Hale-Bopp is photodissociation of $\mathrm{CO}_{2}$ rather than photodissociation of $\mathrm{H}_{2} \mathrm{O}$. Since the relative abundance of $\mathrm{CO}_{2}$ in comet Hyakutake is $1 \%$, the photodissociation of $\mathrm{CO}_{2}$ becomes an important source only near the surface of the nucleus (cf. Figure 6 of Bhardwaj and Raghuram, 2012). The production peak of $\mathrm{O}\left({ }^{1} \mathrm{~S}\right)$ in comet Hyakutake is closer to the nucleus $(<20$ $\mathrm{km})$, whereas in comet Hale-Bopp it is between 100 and 1000 $\mathrm{km}$. Even when we reduced the $\mathrm{CO}_{2}$ abundance by $50 \%$ in Hale-Bopp, the peak production of $\mathrm{O}\left({ }^{1} \mathrm{~S}\right)$ in the inner coma is mainly controlled by photodissociation of $\mathrm{CO}_{2}$ and not by photodissociation of $\mathrm{H}_{2} \mathrm{O}$. Hence, in a high water production rate comet a small relative abundance $(\sim 5 \%)$ of $\mathrm{CO}_{2}$, makes $\mathrm{CO}_{2}$ as a potentially important source of $\mathrm{O}\left({ }^{1} \mathrm{~S}\right)$ compared to $\mathrm{H}_{2} \mathrm{O}$.

In comet Hyakutake, inside $10^{5} \mathrm{~km}$, the photodissociation of $\mathrm{H}_{2} \mathrm{O}$ is the major (more than $90 \%$ ) production process of $\mathrm{O}\left({ }^{1} \mathrm{D}\right)$ formation and the contributions from other processes are very small. But in comet Hale-Bopp, since the $\mathrm{H}_{2} \mathrm{O}$ production rate and $\mathrm{CO}_{2}$ relative abundance are higher, the solar photons of wavelength 955-1165 $\AA$, which are less attenuated by $\mathrm{H}_{2} \mathrm{O}$, can travel deeper into the cometary coma and dissociate the $\mathrm{CO}_{2}$ to form $\mathrm{O}\left({ }^{1} \mathrm{D}\right)$, which is not the case in comet Hyakutake.

The radius of collisional coma, which is a function of total gas production rate, in comets Hyakutake and Hale-Bopp differs by an order of magnitude. In comet Hyakutake quenching of $\mathrm{O}\left({ }^{1} \mathrm{~S}\right)$ by $\mathrm{H}_{2} \mathrm{O}$ is the main destruction mechanism only close to the nucleus $(<50 \mathrm{~km})$ and radiative decay dominates at distances larger than $100 \mathrm{~km}$. However, in comet HaleBopp collisional quenching is significant up to $500 \mathrm{~km}$ and only above that radiative decay is the major loss mechanism of $\mathrm{O}\left({ }^{1} \mathrm{~S}\right)$. Similarly, the collisional quenching radii of $\mathrm{O}\left({ }^{1} \mathrm{D}\right)$ in comets Hyakutake $\left(\sim 10^{3} \mathrm{~km}\right)$ and Hale-Bopp $\left(\sim 10^{4} \mathrm{~km}\right)$ also differs by an order of magnitude.

The $\mathrm{O}\left({ }^{1} \mathrm{D}\right)$ density peak in comet Hale-Bopp is broader (2000 to $5000 \mathrm{~km}$ ) than that in comet Hyakutake (200 to $600 \mathrm{~km})$. This change in the peak distribution of $\mathrm{O}\left({ }^{1} \mathrm{D}\right)$ in the two comets is due to different $\mathrm{H}_{2} \mathrm{O}$ production rates and wavelength dependent photo-attenuation in the cometary comae.

\subsection{Comparison of model calculations with observations}

\subsection{1 [OI] $6300 \AA ̊$ emission}

Morgenthaler et al. (2001) observed [OI] $6300 \AA$ emission on comet Hale-Bopp on several days during February to April 1997 using 4 different ground based instruments. Large aperture observations of $6300 \AA$ emission using WHAM and Hydra spectrometers are made for the field of view $1^{\circ}$ and $45^{\prime}$, which covers projected distances of $1.5 \times 10^{6}$ and $2.4 \times 10^{5} \mathrm{~km}$ on the comet, respectively. Our model calculated brightness profile of [OI] $6300 \AA$ emission shown in Figure 11 is consistent with these observations. The brightness profile of [OI] 5577 $\AA$ starts falling off beyond $1000 \mathrm{~km}$, while the [OI] $6300 \AA$ 
Table 4: The model calculated intensities of forbidden atomic oxygen emission lines on comet Hale-Bopp and the comparison of [OI] $6300 \AA$ line with the observation of Morgenthaler et al. (2001) with $3 \% \mathrm{CO}_{2}$ and $24 \% \mathrm{CO}$.

\begin{tabular}{lccccccc}
\hline Date on & $\mathrm{r}$ & $\Delta$ & \multicolumn{5}{c}{ Intensity $(\mathrm{R})$} \\
\cline { 5 - 8 } 1997 & $(\mathrm{AU})$ & $(\mathrm{AU})$ & $2972 \AA$ & $5577 \AA$ & $6364 \AA$ & \multicolumn{3}{c}{$6300 \AA$} \\
\hline Mar 9 & 0.999 & 1.383 & 34 & 330 & 1162 & 3637 & $2580-2922$ \\
Mar 10 & 0.992 & 1.373 & 36 & 339 & 1192 & 3730 & $2300-2649$ \\
Apr 7 & 0.920 & 1.408 & 45 & 423 & 1422 & 4450 & $2915-4964$ \\
Apr 8 & 0.923 & 1.420 & 43 & 416 & 1400 & 4379 & $3057-3496$ \\
Apr 9 & 0.925 & 1.431 & 43 & 411 & 1380 & 4323 & $2920-3197$ \\
Apr 10 & 0.928 & 1.444 & 43 & 403 & 1358 & 4248 & $1579-1669$ \\
Apr 13 & 0.939 & 1.484 & 39 & 372 & 1271 & 3296 & $1451-1960$ \\
Apr 14 & 0.943 & 1.497 & 37 & 361 & 1240 & 3878 & $1575-2360$ \\
Apr 16 & 0.952 & 1.526 & 36 & 339 & 1179 & 3688 & $2335-2974$ \\
\hline
\end{tabular}

\$The calculated average surface brightness over the observed projected distance of $2.5 \times 10^{5} \mathrm{~km}$.

$\S^{\S}$ The upper and lower limits of [OI] $6300 \AA$ intensity observed by Morgenthaler et al. (2001).

profile remains constant up to $5000 \mathrm{~km}$. The flatness in the calculated surface brightness profiles mainly depends on the collisional quenching of metastable species which is a function of $\mathrm{H}_{2} \mathrm{O}$ production rate. The calculated green and red-doublet emission intensities (dotted lines in Fig. 11) when radiative decay is considered as the only loss mechanism shows the role of collisional quenching. Since the lifetime is relatively larger, the $\mathrm{O}\left({ }^{1} \mathrm{D}\right)$ is substantially quenched by $\mathrm{H}_{2} \mathrm{O}$ in the inner coma. Hence, below $1000 \mathrm{~km}$, the calculated [OI] $6300 \AA$ emission intensities differ by a factor of 5 .

We also calculated the [OI] $6300 \AA$ emission intensity for a circular aperture of $4^{\prime}$ diameter on different days of March and April 1997 similar to the observation conditions of Morgenthaler et al. (2001). The calculated intensities of different atomic oxygen emissions are presented in Table 4 along with the [OI] $6300 \AA$ emission intensities observed by Morgenthaler et al. (2001). Our calculated intensities are higher by a factor of 1.5 to 2.5 compared to the observation and also vary for different days due to change in solar flux, $\mathrm{H}_{2} \mathrm{O}$ production rate, and heliocentric and geocentric distances. The observed [OI] $6300 \AA$ intensity on comet Hale-Bopp on 7 April 1997 is found to vary by a factor of 1.6 in a span of less than 20 minutes, which is difficult to explain with the variation of heliocentric dependent water production rate. Similarly, the observed intensity values on the other days of observation also show large variation. The brightness during April 10 to 14 is consistently lower than during April 7 to 9. The variation in the observed intensity might be associated with spectral extraction process because of non uniform sensitivity of Fabry-Pérot spectrometer (Morgenthaler et al., 2001), rather than the intrinsic variation in the comet.

\subsubsection{Green to red-doublet intensity ratio}

Zhang et al. (2001) observed comet Hale-Bopp on 26 March 1997 using a rectangular slit $\left(1.06^{\prime \prime} \times 3.18^{\prime \prime}\right)$ when the comet was at a geocentric distance of 1.32 AU and heliocentric distance of $0.92 \mathrm{AU}$. For this observation, the projected field of view on the comet was $522 \times 1566 \mathrm{~km}$. Our calculated G/R ratio with $3 \%$ relative abundance of $\mathrm{CO}_{2}$ and $0.5 \%$ yield of $\mathrm{O}\left({ }^{1} \mathrm{~S}\right)$ is 0.21 , which is consistent with the observed $\mathrm{G} / \mathrm{R}$ ratio range $(0.18-0.22)$ of Zhang et al. (2001). The calculated average $\mathrm{G} / \mathrm{R}$ ratio, for a $4^{\prime}$ circular aperture field of view with $3 \%$ relative abundance of $\mathrm{CO}_{2}$ for the different days of observation presented in Table 4 , is around 0.1 . This shows that in a high water production rate comet the observed $\mathrm{G} / \mathrm{R}$ ratio over a large projected distances $\left(\sim 10^{4} \mathrm{~km}\right)$ can be around 0.1 (cf. Fig. 12). However, the calculated contributions of different production processes for $\mathrm{O}\left({ }^{1} \mathrm{~S}\right)$ suggest that photodissociation of $\mathrm{CO}_{2}$ is more important source rather than the photodissociation of $\mathrm{H}_{2} \mathrm{O}$. Hence, in comets with sufficient $\mathrm{CO}_{2}$ abundances $(\geq 5 \%)$, the green line emission is largely controlled by photodissociation of $\mathrm{CO}_{2}$ and the derived $\mathrm{G} / \mathrm{R}$ ratio over large cometocentric distances could be around 0.1 .

Table 5: The model calculated green and red-doublet emission intensities and the derived $\mathrm{O}\left({ }^{1} \mathrm{D}\right)$ and $\mathrm{H}_{2} \mathrm{O}$ production rates for different slit dimensions. The calculations are done with $\mathrm{Q}\left(\mathrm{H}_{2} \mathrm{O}\right)=8.3 \times 10^{30} \mathrm{~s}^{-1}$ for the relative abundances of $6 \%$ $\mathrm{CO}_{2}$ and $24 \% \mathrm{CO}$ at $\mathrm{r}_{h}=1 \mathrm{AU}$ and $\Delta=1 \mathrm{AU}$ using solar flux on 10 April 1997 (solar minimum period : solar radio flux $\left.\mathrm{F} 10.7=74.7 \times 10^{-22} \mathrm{~J} \mathrm{~s}^{-1} \mathrm{~m}^{-2} \mathrm{~Hz}^{-1}\right)$.

\begin{tabular}{cccccc}
\hline Slit dimension & \multicolumn{2}{c}{ Average intensity $(\mathrm{R})^{\dagger}$} & \multicolumn{2}{c}{ Production rate $\left(\mathrm{s}^{-1}\right)$} & \multirow{2}{*}{$\mathrm{G} / \mathrm{R}^{* *}$} \\
\cline { 2 - 5 }$($ Projected distance in km) & {$[\mathrm{OI}] 6300 \AA$} & {$[\mathrm{OI}] 5577 \AA$} & $\mathrm{Q}\left[\mathrm{O}\left({ }^{1} \mathrm{D}\right)\right]$ & $\mathrm{Q}\left[\mathrm{H}_{2} \mathrm{O}\right]^{\ddagger}$ & \\
\hline $2^{\prime \prime} \times 2^{\prime \prime}(725)$ & $18895[83188]^{*}$ & $7584[9245]$ & $1.3 \times 10^{26}$ & $3.7 \times 10^{26}$ & $0.30(0.08)^{\dagger \dagger}$ \\
$5^{\prime \prime} \times 5^{\prime \prime}\left(1.8 \times 10^{3}\right)$ & $18909[68301]$ & $6723[7584]$ & $8.1 \times 10^{26}$ & $23 \times 10^{26}$ & $0.21(0.08)$ \\
$10^{\prime \prime} \times 10^{\prime \prime}\left(3.6 \times 10^{3}\right)$ & $19021[52977]$ & $5369[5825]$ & $3.3 \times 10^{27}$ & $9.3 \times 10^{27}$ & $0.21(0.08)$ \\
$30^{\prime \prime} \times 30^{\prime \prime}\left(1.1 \times 10^{4}\right)$ & $15668[29341]$ & $2963[3118]$ & $2.5 \times 10^{28}$ & $7.1 \times 10^{28}$ & $0.14(0.08)$ \\
$1^{\prime} \times 1^{\prime}\left(2.2 \times 10^{4}\right)$ & $11785[18793]$ & $1846[1924]$ & $7.6 \times 10^{28}$ & $2.1 \times 10^{29}$ & $0.10(0.08)$ \\
$4^{\prime} \times 4^{\prime}\left(8.7 \times 10^{4}\right)$ & $5005[6767]$ & $605[624]$ & $5.0 \times 10^{29}$ & $1.4 \times 10^{30}$ & $0.09(0.07)$ \\
$10^{\prime} \times 10^{\prime}\left(2.1 \times 10^{5}\right)$ & $2351[3056]$ & $263[271]$ & $1.4 \times 10^{30}$ & $3.9 \times 10^{30}$ & $0.08(0.07)$ \\
\hline
\end{tabular}

* The values in the square brackets are the calculated intensities without accounting for collisional quenching of $\mathrm{O}\left({ }^{1} \mathrm{~S}\right)$ and $\mathrm{O}\left({ }^{1} \mathrm{D}\right)$. ${ }^{\dagger}$ Intensity is averaged over the projected field of view, $1 \mathrm{R}=\frac{10^{6}}{4 \pi}$ Photons $\mathrm{s}^{-1} \mathrm{~cm}^{-2} \mathrm{sr}^{-1}$; ${ }^{\ddagger}$ The branching ratio for the production of $\mathrm{O}\left({ }^{1} \mathrm{D}\right)$ in the photodissociation of $\mathrm{OH}$ is taken as 0.357 (see Morgenthaler et al., 2001), while for the photodissociation of $\mathrm{H}_{2} \mathrm{O}$ producing $\mathrm{O}\left({ }^{1} \mathrm{D}\right)$ it is 0.064 (This work). The branching ratio $(0.81)$ for the production of $\mathrm{OH}$ in photodissociation of $\mathrm{H}_{2} \mathrm{O}$ is taken from Huebner et al. (1992). ${ }^{* *}$ Green to red-doublet emission intensity ratio determined over the projected field of view. ${ }^{\dagger \dagger}$ The calculated $\mathrm{G} / \mathrm{R}$ ratio without collisional quenching.

To evaluate the role of slit dimension in determining the $\mathrm{G} / \mathrm{R}$ ratio we calculated green and red line intensities for various slit sizes by keeping $\mathrm{H}_{2} \mathrm{O}, \mathrm{CO}$ and $\mathrm{CO}_{2}$ production rates as a constant. These calculations are presented in Table 5. By varying the slit dimension from $2^{\prime \prime} \times 2^{\prime \prime}$ to $10^{\prime} \times 10^{\prime}$ the calculated $\mathrm{G} / \mathrm{R}$ ratio over the projected cometary coma changed from 0.3 to 0.08 . This result clearly shows that the $\mathrm{G} / \mathrm{R}$ ratio depends not only on the photo-chemistry in the coma but also on the projected area observed for the comet. The calculated $\mathrm{G} / \mathrm{R}$ ratio is a constant value (0.08) throughout the cometary coma when collisional quenching is neglected in the model. By doubling the $\mathrm{CO}_{2}$ relative abundance in the coma, the $\mathrm{G} / \mathrm{R}$ ratio increases by $30 \%$ whereas the collisional quenching of $\mathrm{O}\left({ }^{1} \mathrm{D}\right)$ and $\mathrm{O}\left({ }^{1} \mathrm{~S}\right)$ can change its value even by an order of magnitude. 
Besides the dimension of the slit used for observation, the projected area observed on the comet depends on geocentric distance of the comet. Hence in a comet, where the collisional coma is resolvable in the observation, the derived $\mathrm{G} / \mathrm{R}$ ratio depends on the projected area and also on the collisional quenching of $\mathrm{O}\left({ }^{1} \mathrm{~S}\right)$ and $\mathrm{O}\left({ }^{1} \mathrm{D}\right)$ in the cometary coma. Thus, we conclude that the observed $\mathrm{G} / \mathrm{R}$ ratio of 0.1 is not a definitive benchmark value to verify $\mathrm{H}_{2} \mathrm{O}$ or $\mathrm{CO}_{2} / \mathrm{CO}$ as the parent sources of atomic oxygen visible emissions in comets.

\subsubsection{Width of green and red-doublet emission lines}

Cochran (2008) has found that the width of green line is higher than either of the red-doublet lines in the spectra of 8 comets. The wider green line implies the higher mean velocity of metastable $\mathrm{O}\left({ }^{1} \mathrm{~S}\right)$, which could be associated with different production processes. Besides collisions with different cometary species, the mean velocity of $\mathrm{O}\left({ }^{1} \mathrm{~S}\right)$ in the cometary coma is determined by various production processes, and/or could be due to the involvement of photons of various energies in dissociating O-bearing species (Cochran, 2008).

The observed width of forbidden line emission depends on the velocity distribution of radiating metastable oxygen atoms. We found that the excess velocity released in photodissociation $\mathrm{H}_{2} \mathrm{O}$ in the unity radiative efficiency region is $2.1 \mathrm{eV}$ (cf. Figure 14). If we assume that most of this excess energy is transfered to kinetic motion of atomic oxygen then the maximum mean velocity that can be acquired by the $\mathrm{O}\left({ }^{1} \mathrm{D}\right)$ atom would be $1.6 \mathrm{~km} \mathrm{~s}^{-1}$. This velocity is consistent with values of 0.5 to $1.8 \mathrm{~km} \mathrm{~s}^{-1}$ derived by Cochran (2008) in 8 comets. This supports the idea that most of the red-doublet emission in cometary coma is governed by the photodissociation of $\mathrm{H}_{2} \mathrm{O}$. The excess energy profiles shown in Figure 14 suggest that the $\mathrm{O}\left({ }^{1} \mathrm{D}\right)$ produced in photodissociation of $\mathrm{CO}$ and $\mathrm{CO}_{2}$ will have higher velocity than that produced in photodissociation of $\mathrm{H}_{2} \mathrm{O}$. The excess energy released in the photodissociation of $\mathrm{CO}$ and $\mathrm{CO}_{2}$ in the unity radiative efficiency region is 2.5 $\mathrm{eV}$ and $4.1 \mathrm{eV}$, which corresponds to $\mathrm{O}\left({ }^{1} \mathrm{D}\right)$ excess velocity of $\sim 3.7 \mathrm{~km} \mathrm{~s}^{-1}$ and $4 \mathrm{~km} \mathrm{~s}^{-1}$, respectively. However, our calculations suggest that $\mathrm{CO}$ and $\mathrm{CO}_{2}$ together can contribute to a maximum of $10 \%$ to the red-doublet emission. The contributions of $\mathrm{CO}$ and $\mathrm{CO}_{2}$ in the wings of red-doublet lines are probable.

In the case of green line emission, since there is no experimentally determined cross section or yield for the photodissociation of $\mathrm{H}_{2} \mathrm{O}$ producing $\mathrm{O}\left({ }^{1} \mathrm{~S}\right)$, it is difficult to determine the mean velocity acquired by an $\mathrm{O}\left({ }^{1} \mathrm{~S}\right)$ atom in the the photolysis of $\mathrm{H}_{2} \mathrm{O}$. The maximum excess energy that can be released in photolysis of $\mathrm{H}_{2} \mathrm{O}$ producing $\mathrm{O}\left({ }^{1} \mathrm{~S}\right)$ at solar $\mathrm{H} \mathrm{Ly}-\alpha$ is 1.27 $\mathrm{eV}$. Again, if we assume all the excess energy is transferred as kinetic energy of atomic oxygen in ${ }^{1} \mathrm{~S}$ state then the maximum excess velocity of $\mathrm{O}\left({ }^{1} \mathrm{~S}\right)$ would be $1.3 \mathrm{~km} \mathrm{~s}^{-1}$. But in the case of photodissociation of $\mathrm{CO}_{2}$, the excess energy is $2.5 \mathrm{eV}$, which corresponds to a maximum $\mathrm{O}\left({ }^{1} \mathrm{~S}\right)$ velocity of $4.3 \mathrm{~km} \mathrm{~s}^{-1}$. The dissociative recombination of ions $\mathrm{H}_{2} \mathrm{O}^{+}, \mathrm{CO}_{2}^{+}$, and $\mathrm{CO}^{+}$can contribute a maximum of $30 \%$ in the production of green line emission. But the excess energy released in these recombination reactions is very small (Rosén et al., 2000, 1998; Seiersen et al., 2003). By assuming that the maximum mean velocity that can be acquired by $\mathrm{O}\left({ }^{1} \mathrm{~S}\right)$ via the dissociative recombination processes is about $1 \mathrm{~km} \mathrm{~s}^{-1}$, we found that the mean velocity of $\mathrm{O}\left({ }^{1} \mathrm{~S}\right)$ from all production processes is $\sim 2 \mathrm{~km} \mathrm{~s}^{-1}$. This value is consistent with the derived velocity range of 1.9 to $3.1 \mathrm{~km} \mathrm{~s}^{-1}$ for $\mathrm{O}\left({ }^{1} \mathrm{~S}\right)$ in 8 comets by Cochran (2008).

Before coming to a broad conclusion, we suggest that one has to calculate the exact mean excess velocities of $\mathrm{O}\left({ }^{1} \mathrm{~S}\right)$ and $\mathrm{O}\left({ }^{1} \mathrm{D}\right)$ over the observed cometary coma, by accounting for all collisional processes and the mean excess velocity profiles of various species. Due to non availability of photon cross sections for some of the photodissociation processes, and uncertainties involved in the excess energy calculations for dissociative recombination reactions, our model is limited in determining the exact line widths of green and red-doublet emissions. However, based on our model calculations on comets Hale-Bopp and Hyakutake, we suggest that involvement of multiple sources in the formation $\mathrm{O}\left({ }^{1} \mathrm{~S}\right)$ could be a potential reason for the higher line width of green emission compared to that of red-doublet emission observed in several comets.

\subsection{Effect of model parameters on the calcu- lated intensities}

\subsubsection{Expansion velocity of neutrals}

As we mentioned earlier in the Section 2, we have used the velocity profile from the work of Combi et al. (1999) for calculating the number densities of parent species $\mathrm{H}_{2} \mathrm{O}, \mathrm{CO}_{2}$, and CO. Combi et al. (1999) have shown that there is an acceleration of neutrals in the inner coma due to the photolytic heating (Combi et al., 1999; Colom et al., 1999; Biver et al., 1997; Combi, 2002) and other processes (Harris et al., 2002). To evaluate the impact of this acceleration on our model results we carried out calculations by taking a constant gas expansion velocity profile with the values 0.7 and $2.2 \mathrm{~km} \mathrm{~s}^{-1}$. By using a constant velocity profile of $0.7 \mathrm{~km} \mathrm{~s}^{-1}$ in the coma, rather than a radially varying velocity of Combi et al. (1999), the calculated intensities of green and red-doublet emissions are increased by $30 \%$ and $25 \%$, respectively, which are still higher than the observation. By changing the constant gas expansion velocity from 0.7 to $2.2 \mathrm{~km} \mathrm{~s}^{-1}$, the calculated intensities of atomic oxygen emission lines are decreased by $\sim 50 \%$. However using the Combi et al. (1999) velocity profile, our calculated [OI] $6300 \AA$ A emission intensities over $4^{\prime}$ circular aperture field of view are closer to the observation (cf. Table 4 ). Hence, the velocity profile of neutral species is an important input in the model that should be accounted in calculating the intensities of these forbidden emissions.

\subsubsection{Relative abundances of neutral species}

The water production rate in comet Hale-Bopp has been derived using emissions of direct and daughter products of $\mathrm{H}_{2} \mathrm{O}$ by different observers (Weaver et al., 1997; Colom et al., 1999; Schleicher et al., 1997; Combi et al., 2000; Dello Russo et al., 2000; Woods et al., 2000; Morgenthaler et al., 2001; Harris et al., 2002; Fink, 2009). During the observation period of these green and red-doublet emissions $\left(\mathrm{r}_{h}\right.$ of the comet was around 0.9 AU), Dello Russo et al. (2000) measured the $\mathrm{H}_{2} \mathrm{O}$ production rates using infrared emissions of water molecules 
for different days. In this period, Combi et al. (2000) derived the $\mathrm{H}_{2} \mathrm{O}$ production rate in this comet using $\mathrm{H}$ Ly- $\alpha$ emission. The difference between these two derived production rates is less than $20 \%$. These observations found that around $1 \mathrm{AU}$ the water production rate in comet Hale-Bopp was about $\sim 1 \times 10^{31} \mathrm{~s}^{-1}$. Similarly, the derived water production rates of Fink (2009) on 1997 March 3 was $6.1 \times 10^{30}$ $\mathrm{s}^{-1}$ which is smaller than the Combi et al. (2000) derived rate by a factor of 1.5. Using visible emission of atomic oxygen Morgenthaler et al. (2001) derived the $\mathrm{H}_{2} \mathrm{O}$ production rates by applying standard branching ratios of $\mathrm{OH}$ and $\mathrm{H}_{2} \mathrm{O}$. These derived $\mathrm{H}_{2} \mathrm{O}$ production rates are higher by factor of 3 to 6 compared to values determined from other observations. To assess the impact of $\mathrm{H}_{2} \mathrm{O}$ production rate on the calculated green and red-doublet emissions we increased its value by a factor of 5. With increase in $\mathrm{H}_{2} \mathrm{O}$ production rate the model calculated surface brightness of green and red-doublet emissions over $4^{\prime}$ circular field of view is increased by a factor of 3.

As demonstrated earlier in this paper, the role of $\mathrm{CO}_{2}$ is very significant in determining the green line emission intensity and subsequently the $G / R$ ratio. During the observation period of these forbidden emission lines the $\mathrm{CO}_{2}$ is not observed in this comet. To evaluate the impact of $\mathrm{CO}_{2}$ we varied its relative abundance from 3 to $6 \%$. We found an increase (25\%) in the calculated green line emission intensity over the $4^{\prime}$ circular aperture field of view whereas it is small $(<5 \%)$ for red-doublet emission intensity.

Based on infrared observations made near perihelion on comet Hale-Bopp, DiSanti et al. (2001) suggested that $50 \%$ of $\mathrm{CO}$ abundance present in the cometary coma is contributed by distributed sources. Bockelée-Morvan et al. (2010) investigated the extended distribution of $\mathrm{CO}$ by probing Hale-Bopp between $\sim 800$ to $\sim 20,000 \mathrm{~km}$ region using CO rotational line emissions (viz, CO J(1-0) and CO J(2-1)). Based on the observation and radiative transfer modelling studies, BockeléeMorvan et al. (2010) rejected the idea of an extended distribution of $\mathrm{CO}$ in Hale-Bopp. Since the contribution of photodissociation of $\mathrm{CO}$ to formation of $\mathrm{O}\left({ }^{1} \mathrm{~S}\right)$ and $\mathrm{O}\left({ }^{1} \mathrm{D}\right)$ is less than $10 \%$, no significant variation in the calculated intensity of green and red-doublet emissions is found by reducing the $\mathrm{CO}$ relative abundance by half. Hence, the involvement of $\mathrm{CO}$ in these oxygen forbidden line emissions is almost insignificant.

Though $\mathrm{OH}$ column densities are determined using 3080 $\AA$ surface brightness profile, there are large uncertainties in photo-cross sections of $\mathrm{OH}$ in producing $\mathrm{O}\left({ }^{1} \mathrm{D}\right)$ and $\mathrm{O}\left({ }^{1} \mathrm{~S}\right)$ (Huebner et al., 1992; Morgenthaler et al., 2001). The calculated photo-rates for the production of $\mathrm{O}\left({ }^{1} \mathrm{D}\right)$ via photodissociation of $\mathrm{OH}$, using theoretical and experimental cross sections differ by about an order of magnitude (Huebner et al., 1992). Morgenthaler et al. (2001) studied the effect of these cross sections in deriving the $\mathrm{H}_{2} \mathrm{O}$ production rates using 6300 $\AA$ surface brightness profile and found that on using the theoretical $\mathrm{OH}$ photodissociative branching ratios of $\mathrm{O}\left({ }^{1} \mathrm{D}\right)$, the derived $\mathrm{H}_{2} \mathrm{O}$ production rates are higher by a factor of 3-6, than those determined based on experimental branching ratios of Nee and Lee (1984). The photodissociation of $\mathrm{OH}$ influences the calculated green and red-doublet emission intensities significantly above $10^{4} \mathrm{~km}$ (cf. Figs. 2 and 5, and
Table 2). By changing photorates determined by Nee and Lee (1984) experimental cross sections (which are used in the model) with the rates derived based on theoretically calculated cross sections of van Dishoeck and Dalgarno (1984), we found a $40 \%$ decrease in the calculated slit-averaged brightness over the $4^{\prime}$ circular aperture field of view for both green and red-doublet emissions. But the calculated $\mathrm{O}\left({ }^{1} \mathrm{~S}\right)$ and $\mathrm{O}\left({ }^{1} \mathrm{D}\right)$ production rates along the radial distances are decreased by an order of magnitude above $10^{4} \mathrm{~km}$. Since $\mathrm{OH}$ is the dominant O-bearing species in the outer coma, the cross sections can affect the calculated the surface brightness of [OI] $6300 \AA$ at larger projected distances $\left(>10^{5} \mathrm{~km}\right)$. To fit the observed [OI] $6300 \AA$ emission in the outer coma Glinski et al. (2004) found it necessary to increase theoretical determined $\mathrm{OH}$ to $\mathrm{O}\left({ }^{1} \mathrm{D}\right)$ photorate by a factor of around 3 .

The chemistry model developed by Glinski et al. (2004) suggested that the collisions of $\mathrm{O}\left({ }^{3} \mathrm{P}\right)$ with $\mathrm{OH}$ leads to the formation of $\mathrm{O}_{2}$. These calculations also showed that the $\mathrm{O}_{2}$ densities can be as high as $1 \%$ of $\mathrm{H}_{2} \mathrm{O}$. We evaluated the change in green and red-doublet emission intensities by incorporating $\mathrm{O}_{2}$ in the model by taking its density profiles from Glinski et al. (2004). No significant change $(<5 \%)$ is found in the green and red-doublet emission intensities by including $\mathrm{O}_{2}$ in the model. This is because the other O-bearing species are several orders of magnitude higher in the inner coma.

\subsubsection{Effect of slit dimension on the derived $O\left({ }^{1} \mathrm{D}\right)$ production rate}

As a case study, for a fixed $\mathrm{H}_{2} \mathrm{O}$ production rate and $\mathrm{CO}$ and $\mathrm{CO}_{2}$ relative abundances, we calculated [OI] $6300 \AA$ emission intensity over a projected field of view for different slit dimensions. We then derived the $\mathrm{O}\left({ }^{1} \mathrm{D}\right)$ production rate based on the calculated average [OI] 6300 emission intensity over the projected field view. These calculations are presented in Table 5. Since our model calculations are limited up to the projected distances of $10^{5} \mathrm{~km}$ (which is discussed in Section 4.3) we present the calculated intensities of [OI] 6300 and 5577 $\AA$ emissions for the slit dimension up to $10^{\prime} \times 10^{\prime}$. Though $\mathrm{O}\left({ }^{1} \mathrm{D}\right)$ is substantially produced in the inner coma via photodissociation, the collisional quenching by cometary species results in a very few [OI] $6300 \AA$ photons. The role of quenching in determining the [OI] $6300 \AA$ flux can be understood from the calculated values presented in Table 5. A large aperture observation is required, which covers the entire [OI] 6300 $\AA$ emission region, to derive the $\mathrm{H}_{2} \mathrm{O}$ production rate. The calculations presented in Table 5 suggest that by using large aperture slit the derived water production rate is closer to the actual production rate of $\mathrm{H}_{2} \mathrm{O}$. Hence, to derive the water production rate using [OI] $6300 \AA$, the slit dimension which covers a projected distance more than the scale length of $\mathrm{H}_{2} \mathrm{O}$ should be used.

\subsection{Limitations and future scope of the model}

The density of the species produced in the inner coma (radial distances less than $10^{5} \mathrm{~km}$ ) is mainly controlled by photochemical reactions. Above these distances the transport of 
species starts becoming significant in determining the number density of the calculated species. Our model calculations are based on photochemical equilibrium condition and is for a collisional coma. Hence, model results presented at distances beyond $5 \times 10^{5} \mathrm{~km}$ are not as reliable as the values in the inner coma. Moreover, above these radial distances the chemical lifetimes of neutral species are significantly altered by the solar wind interaction through charge exchange and impact ionization processes. Also, we could not incorporate altitude distribution of dust density in our model calculations which can affect the calculated optical depth. Since our model is time independent and one dimensional it is difficult to explain the asymmetry in the observed [OI] $6300 \AA$ emission intensity over the cometary coma. For determining the spectral width of green and red-doublet lines elaborated calculations are required along with laboratory measured photodissociation cross sections.

\section{Summary and Conclusions}

We have recently developed a coupled chemistry-emission model for the forbidden visible emissions 5577 and $6300 \AA$ of atomic oxygen in comet C/1996 B2 Hyakutake (Bhardwaj and Raghuram, 2012). In the present paper we applied our model to a high ( 30 times more than on Hyakutake) gas production rate comet $\mathrm{C} / 1995 \mathrm{O} 1$ Hale-Bopp in which these prompt emissions are observed in 1997 by Morgenthaler et al. (2001) and Zhang et al. (2001). The main results of our model calculations on comet Hale-Bopp are summarized as follows.

1. Below cometocentric distance of $10^{3} \mathrm{~km}$, photodissociation of $\mathrm{CO}_{2}$ is the major production mechanism of $\mathrm{O}\left({ }^{1} \mathrm{~S}\right)$. Between $10^{3}$ and $10^{4} \mathrm{~km}$, the contributions from the photodissociation of $\mathrm{CO}_{2}$ and $\mathrm{H}_{2} \mathrm{O}$ are nearly equal. Above $2 \times 10^{4} \mathrm{~km}$ several other processes are also significant to the $\mathrm{O}\left({ }^{1} \mathrm{~S}\right)$ production.

2. Mainly the solar photons in $955-1165 \AA$ wavelength band contribute to the production of $\mathrm{O}\left({ }^{1} \mathrm{~S}\right)$ in photodissociation of $\mathrm{CO}_{2}$. This is because the yield of $\mathrm{O}\left({ }^{1} \mathrm{~S}\right)$ in $\mathrm{CO}_{2}$ photodissociation reaches a maximum in this wavelength region.

3. Since the cross section of photodissociation of $\mathrm{CO}_{2}$ for the production of $\mathrm{O}\left({ }^{1} \mathrm{~S}\right)$ is more than two orders of magnitude larger than that of $\mathrm{H}_{2} \mathrm{O}$, even a small amount (few percent relative abundance) of $\mathrm{CO}_{2}$ can make it an important source of the $\mathrm{O}\left({ }^{1} \mathrm{~S}\right)$.

4. Quenching by $\mathrm{H}_{2} \mathrm{O}$ is the main loss mechanism for $\mathrm{O}\left({ }^{1} \mathrm{~S}\right)$ at radial distances below $300 \mathrm{~km}$; above $10^{3} \mathrm{~km}$ radiative decay via $5577 \AA$ emission is the dominant destruction mechanism.

5. Inside $10^{5} \mathrm{~km}$, the main production mechanism of $\mathrm{O}\left({ }^{1} \mathrm{D}\right)$ is photodissociation of $\mathrm{H}_{2} \mathrm{O}$; but, in the innermost part of the coma $(<100 \mathrm{~km})$ the photodissociation of $\mathrm{CO}_{2}$ is also a significant source.

6. For photodissociation of $\mathrm{H}_{2} \mathrm{O}$, the peak $\mathrm{O}\left({ }^{1} \mathrm{D}\right)$ production occurs via H Ly- $\alpha$ (1216 ̊), 1165-1375 $\AA$ and 1375-1575
$\AA$ wavelength bands at cometocentric distances of 1000 , 200 , and $50 \mathrm{~km}$, respectively. Solar photons at all other wavelengths produce $\mathrm{O}\left({ }^{1} \mathrm{D}\right)$ with one or more orders of magnitude smaller efficiency.

7. Below $100 \mathrm{~km}$, solar photons in the wavelength band 1375-1585 A mainly produce $\mathrm{O}\left({ }^{1} \mathrm{D}\right)$ by photodissociation of $\mathrm{CO}_{2}$. The contribution from other wavelength bands is significant above cometocentric distances of $200 \mathrm{~km}$.

8. The major destruction mechanism of $\mathrm{O}\left({ }^{1} \mathrm{D}\right)$ up to 3000 $\mathrm{km}$ cometocentric distance is quenching by $\mathrm{H}_{2} \mathrm{O}$; above $5000 \mathrm{~km}$ radiative decay takes over.

9. In comet Hale-Bopp the $\mathrm{O}\left({ }^{1} \mathrm{D}\right)$ density peaks occurs between $10^{3}$ and $10^{4} \mathrm{~km}$, while for $\mathrm{O}\left({ }^{1} \mathrm{~S}\right)$ the peak is around 500-1000 km.

10. The radiative efficiency of $\mathrm{O}\left({ }^{1} \mathrm{~S}\right)$ and $\mathrm{O}\left({ }^{1} \mathrm{D}\right)$ atoms in comet Hale-Bopp are unity above $10^{3}$ and $10^{4} \mathrm{~km}$, respectively. In comet Hyakutake these distances are $10^{2}$ and $10^{3} \mathrm{~km}$, respectively.

11. The model calculated green to red-doublet emission intensity ratio is consistent with the observation of Zhang et al. (2001)

12. Collisional quenching can change the $\mathrm{G} / \mathrm{R}$ ratio by an order of magnitude, whereas doubling the relative abundance of $\mathrm{CO}_{2}$ increases its value by maximum of $30 \%$.

13. To accurately measure the $\mathrm{H}_{2} \mathrm{O}$ production rate in cometary coma, a slit dimension which covers a projected distance more than the scale length of $\mathrm{H}_{2} \mathrm{O}$ is preferred to cover the entire [OI] $6300 \AA$ emission region.

14. The model calculated [OI] $6300 \AA$ emission intensity profile as a function of projected distance is in agreement with the observation of Morgenthaler et al. (2001). The model calculated surface brightness averaged over a $4^{\prime}$ circular aperture field of view is higher by a factor of 1.5 to 2 compared to the observation.

15. The calculated mean excess velocity of $\mathrm{O}\left({ }^{1} \mathrm{D}\right)$ and $\mathrm{O}\left({ }^{1} \mathrm{~S}\right)$ atoms in the region of unity radiative efficiency is $\sim 1.6$ and $\sim 2 \mathrm{~km} \mathrm{~s}^{-1}$, respectively, which is consistent with the range of velocities observed by Cochran (2008) in several comets.

16. Based on our model calculations for comets Hyakutake and Hale-Bopp, we conclude that [OI] $6300 \AA$ emission is mainly controlled by the photodissociation of $\mathrm{H}_{2} \mathrm{O}$, while the [OI] $5577 \AA$ emission line is contributed by both $\mathrm{H}_{2} \mathrm{O}$ and $\mathrm{CO}_{2}$. Since $\mathrm{O}\left({ }^{1} \mathrm{~S}\right)$ production is associated with different molecules, whereas the $\mathrm{O}\left({ }^{1} \mathrm{D}\right)$ production is mainly from $\mathrm{H}_{2} \mathrm{O}$, the width of the green line will be higher than that of the red-doublet lines.

With a high $\mathrm{H}_{2} \mathrm{O}$ production rate, comet Hale-Bopp provided a large gaseous environment, which has not been seen in previous comets. Since the apparition was at small geocentric distances, the giant cometary coma has provided a laboratory 
for investigating several collisional-driven effects. These collision driven processes are very important in determining the distribution of cometary excited species in the coma, which manifests into the emissions of the cometary coma.

\section{Acknowledgements}

S. Raghuram was supported by the ISRO Senior Research Fellowship during the period of this work. Solar Irradiance Platform historical irradiances are provided courtesy of W. Kent Tobiska and Space Environment Technologies. These historical irradiances have been developed with partial funding from the NASA UARS, TIMED, and SOHO missions. The authors thank the reviewers for their valuable comments and suggestions that has improved the paper significantly.

\section{References}

Atkinson, R., Baulch, D. L., Cox, R. A., Hampson, Jr., R. F., Kerr, J. A., Rossi, M. J., Troe, J., Nov. 1997. Evaluated Kinetic and Photochemical Data for Atmospheric Chemistry: Supplement VI. IUPAC Subcommittee on Gas Kinetic Data Evaluation for Atmospheric Chemistry. Journal of Physical and Chemical Reference Data 26, 1329-1499. doi:10.1063/1.556010.

Bhardwaj, A., 1999. On the role of solar EUV, photoelectrons, and auroral electrons in the chemistry of $\mathrm{C}\left({ }^{1} \mathrm{D}\right)$ and the production of C I $1931 \AA$ in the inner cometary coma: A case for comet P/Halley. J. Geophys. Res. 104, 1929 - 1942. doi:10.1029/1998JE900004.

Bhardwaj, A., 2003. On the solar EUV deposition in the inner coma of comets with large gas production rates. Geophys. Res. Lett. 30 (24). doi:10.1029/2003GL018495.

Bhardwaj, A., Haider, S. A., 1999. Modeling of metastable carbon atoms in comets: implications for ROSETTA. Adv. Space Res. 23 (7), 1325 - 1328.

Bhardwaj, A., Haider, S. A., 2002. Chemistry of $\mathrm{O}\left({ }^{1} \mathrm{D}\right)$ atoms in the coma: implications for cometary missions. Adv. Space Res. 29, 745-750. doi:10.1016/S0273-1177(02)00006-6.

Bhardwaj, A., Haider, S. A., Singhal, R. P., 1990. Auroral and photoelectron fluxes in cometary ionospheres. Icarus 85, 216 - 228. doi:10.1016/0019-1035(90)90112-M.

Bhardwaj, A., Haider, S. A., Singhal, R. P., 1996. Production and emissions of atomic carbon and oxygen in the inner coma of comet 1P/Halley: Role of electron impact. Icarus 120, 412 - 430. doi:10.1006/icar.1996.0061.

Bhardwaj, A., Jain, S. K., 2009. Monte Carlo model of electron energy degradation in a $\mathrm{CO}_{2}$ atmosphere. J. Geophys. Res. 114 (A13), 11309. doi:10.1029/2009JA014298.

Bhardwaj, A., Jain, S. K., 2012. Production of $\mathrm{N}_{2}$ VegardKaplan and other triplet band emissions in the dayglow of Titan. Icarus 218 (2), 989 - 1005. doi: 10.1016/j.icarus.2012.01.019.
Bhardwaj, A., Michael, M., 1999a. Monte Carlo model for electron degradation in $\mathrm{SO}_{2}$ gas: Cross sections, yield spectra and efficiencies. J. Geophys. Res. 104 (10), 24713-24728. doi:10.1029/1999JA900283.

Bhardwaj, A., Michael, M., 1999b. On the excitation of Io's atmosphere by the photoelectrons: Application of the analytical yield spectrum of $\mathrm{SO}_{2}$. Geophys. Res. Lett. 26, 393 - 396. doi:10.1029/1998GL900320.

Bhardwaj, A., Raghuram, S., 2011. Model for Cameron-band emission in comets: A case for the EPOXI mission target comet 103P/Hartley 2. Mon. Not. R. Astron. Soc. 412, L25 - L29. doi:10.1111/j.1745-3933.2010.00998.x.

Bhardwaj, A., Raghuram, S., 2012. A coupled chemistryemission model for atomic oxygen green and red-doublet emissions in the comet C/1996 B2 Hyakutake. Astrophys. J. 748, 13. doi:10.1088/0004-637X/748/1/13.

Bhardwaj, A., Singhal, R. P., 1993. Optically thin H Lyman alpha production on outer planets: Low-energy proton acceleration in parallel electric fields and neutral $\mathrm{H}$ atom precipitation from ring current. J. Geophys. Res. 98 (A6), 9473 - 9481. doi:10.1029/92JA02400.

Biver, N., Bockelée-Morvan, D., Colom, P., Crovisier, J., Davies, J. K., Dent, W. R. F., Despois, D., Gérard, E., Lellouch, E., Rauer, H., Moreno, R., Paubert, G., 1997. Evolution of the outgassing of comet Hale-Bopp (C/1995 O1). Science 275, 1915-1918. doi:10.1023/A:1006229818484.

Biver, N., Bockelee-Morvan, D., Crovisier, J., Davies, J. K., Matthews, H. E., Wink, J. E., Rauer, H., Colom, P., Dent, W. R. F., Despois, D., Moreno, R., Paubert, G., Jewitt, D., Senay, M., 1999. Spectroscopic monitoring of comet C/1996 B2 (Hyakutake) with the JCMT and IRAM radio telescopes. Astron. J. 118, 1850-1872.

Bockelée-Morvan, D., Crovisier, J., Mumma, M. J., Weaver, H. A., 2004. The composition of cometary volatiles: Comets II. pp. 391-423.

Bockelée-Morvan, D., Hartogh, P., Crovisier, J., Vandenbussche, B., Swinyard, B. M., Biver, N., Lis, D. C., Jarchow, C., Moreno, R., Hutsemékers, D., Jehin, E., Küppers, M., Lara, L. M., Lellouch, E., Manfroid, J., de Val-Borro, M., Szutowicz, S., Banaszkiewicz, M., Bensch, F., Blecka, M. I., Emprechtinger, M., Encrenaz, T., Fulton, T., Kidger, M., Rengel, M., Waelkens, C., Bergin, E., Blake, G. A., Blommaert, J. A. D. L., Cernicharo, J., Decin, L., Encrenaz, P., de Graauw, T., Leeks, S., Medvedev, A. S., Naylor, D., Schieder, R., Thomas, N., 2010. A study of the distant activity of comet C/2006 W3 (Christensen) with Herschel and ground-based radio telescopes. Astron. Astrophys. 518 (L149). doi:10.1051/0004-6361/201014655.

Bockelée-Morvan, D., Lis, D. C., Wink, J. E., Despois, D., Crovisier, J., Bachiller, R., Benford, D. J., Biver, N., Colom, P., Davies, J. K., Gérard, E., Germain, B., Houde, M., Mehringer, D., Moreno, R., Paubert, G., Phillips, T. G., Rauer, H., Jan. 2000. New molecules found in comet C/1995 
O1 (Hale-Bopp). Investigating the link between cometary and interstellar material. Astron. Astrophys. 353, 11011114 .

Capria, M. T., Cremonese, G., Bhardwaj, A., de Sanctis, M. C., Nov. 2005. $\mathrm{O}\left({ }^{1} \mathrm{~S}\right)$ and $\mathrm{O}\left({ }^{1} \mathrm{D}\right)$ emission lines in the spectrum of $153 \mathrm{P} / 2002 \mathrm{C} 1$ (Ikeya-Zhang). Astron. Astophys. 442, 1121-1126. doi:10.1051/0004-6361:20053047.

Capria, M. T., Cremonese, G., Bhardwaj, A., Sanctis, M. C. D., Epifani, E. M., 2008. Oxygen emission lines in the high resolution spectra of $9 \mathrm{P} /$ Tempel 1 following the deep impact event. Astron. Astrophys. 479 (1), 257-263. doi: 10.1051/0004-6361:20077072.

Capria, M. T., Cremonese, G., de Sanctis, M. C., Nov. 2010. High resolution observation of $17 \mathrm{P} /$ Holmes during the outburst event in 2007. Astron. Astrophys. 522, A82. doi: 10.1051/0004-6361/200913889.

Cochran, A. L., Nov. 2008. Atomic oxygen in the comae of comets. Icarus 198, 181-188. doi: 10.1016/j.icarus.2008.06.007.

Cochran, A. L., Cochran, W. D., Dec. 2001. Observations of O $\left({ }^{1} \mathrm{~S}\right)$ and $\mathrm{O}\left({ }^{1} \mathrm{D}\right)$ in Spectra of C/1999 S4 (LINEAR). Icarus 154, 381-390. doi:10.1006/icar.2001.6718.

Cochran, W. D., 1984. Detection of [OI ${ }^{1}{ }^{\mathrm{S}-}{ }^{1} \mathrm{D}$ in comet IRASAraki-Alcock . Icarus 58 (3), 440-445. doi:10.1016/00191035(84)90089-7.

Colom, P., Gérard, E., Crovisier, J., Bockelé-Morvan, D., Biver, N., Rauer, H., Jul. 1999. Observations of the $\mathrm{OH}$ Radical in Comet C/1995 O1 (Hale-Bopp) with the Nançay Radio Telescope. Earth Moon and Planets 78, 37-43. doi: 10.1023/A:1006206924786.

Combi, M., 2002. HaleBopp: What makes a big comet different? coma dynamics: Observations and theory. Earth, Moon and Planets 89, 73 - 90 .

Combi, M. R., Kabin, K., DeZeeuw, D. L., Gombosi, T. I., Powell, K. G., 1999. Dust gas interrelations in comets: Observations and theory. Earth, Moon, and Planets 79 (1 - 3), 275 - 306. doi:10.1023/A:1006257922294.

Combi, M. R., Reinard, A. A., Bertaux, J.-L., Quemerais, E., Mäkinen, T., 2000. SOHO/SWAN observations of the structure and evolution of the Hydrogen Lyman- $\alpha$ coma of comet Hale-Bopp (1995 O1). Icarus 144, 191 - 202. doi: 10.1006/icar.1999.6335.

Crovisier, J., Leech, K., Bockelée-Morvan, D., Brooke, T. Y., Hanner, M. S., Altieri, B., Keller, H. U., Lellouch, E., 1997. The spectrum of comet Hale-Bopp (C/1995 O1) observed with the Infrared Space Observatory at 2.9 AU from the Sun. Science 275, 1904 - 1907. doi: 10.1126/science.275.5308.1904.

Dello Russo, N., Mumma, M. J., Disanti, M. A., Magee-Sauer, K., Novak, R., Rettig, T. W., Feb. 2000. Water production and release in comet C/1995 O1 Hale-Bopp. Icarus 143, 324-337.
Delsemme, A. H., Combi, M. R., Nov. 1976. The production rate and possible origin of $\mathrm{O}\left({ }^{1} \mathrm{D}\right)$ in comet Bennett 1970 II. Astrophys. J. Lett. 209, L149. doi:10.1086/182286.

Delsemme, A. H., Combi, M. R., 1979. $\mathrm{O}\left({ }^{1} D\right)$ and $\mathrm{H}_{2}^{+} \mathrm{O}$ in comet Bennett 1970 II. Astrophys. J. 228, 330-337. doi: $10.1086 / 156850$.

DiSanti, M. A., Mumma, M. J., Dello Russo, N., MageeSauer, K., 2001. Carbon Monoxide Production and excitation in comet $\mathrm{C} / 1995 \mathrm{O} 1$ (Hale-Bopp): Isolation of native and distributed CO sources. Icarus 153, 361 - 390. doi: 10.1006/icar.2001.6695.

Festou, M. C., Feldman, P. D., 1981. The forbidden oxygen lines in comets. Astron. Astrophys. 103, $154-159$.

Fink, U., 2009. A taxonomic survey of comet composition 19852004 using CCD spectroscopy. Icarus 201, 311 - 334. doi:10.1016/j.icarus.2008.12.044.

Fink, U., Johnson, J. R., 1984. Luminosity and spatial distribution of the $\mathrm{O}[\mathrm{I}] 6300 \AA$ emission in comets. Astron. J. 89 (10), 1565-1572. doi:10.1086/113660.

Furusho, R., Kawakitab, H., Fusec, T., Watanabe, J., 2006. Forbidden oxygen emission lines of comet 116P/Wild 4 at 2.4 AU . Adv. Space Res. 9, 1983-1986. doi: 10.1016/j.asr.2006.06.003.

Glinski, R. J., Ford, B. J., Harris, W. M., Anderson, C. M., Morgenthaler, J. P., 2004. Oxygen/Hydrogen chemistry in the inner comae of active comets. Astrophys. J. 608, 601609.

Haider, S. A., Bhardwaj, A., 2005. Radial distribution of production rates, loss rates and densities corresponding to ion masses $\leq 40 \mathrm{amu}$ in the inner coma of comet Halley: Composition and chemistry. Icarus 177, 196 - 216. doi: 10.1016/j.icarus.2005.02.019.

Harris, W. M., Scherb, F., Mierkiewicz, E., Oliversen, R., Morgenthaler, J., Oct. 2002. Production, outflow velocity, and radial distribution of $\mathrm{H}_{2} \mathrm{O}$ and $\mathrm{OH}$ in the Coma of comet C/1995 O1 (Hale-Bopp) from wide-field imaging of OH. Astrophys. J. 578, 996-1008. doi:10.1086/342648.

Huebner, W. F., Carpenter, C. W., 1979. Solar photo rate coefficients. Los Alamos Report, 8085.

Huebner, W. F., Keady, J. J., Lyon, S. P., 1992. Solar photorates for planetary atmospheres and atmospheric pollutants. Astrophys. Space Sci. 195 (1), 1-294. doi: $10.1007 / \mathrm{BF} 00644558$.

Huestis, D. L., Slanger, T. G., 2006. DPS. American Astronomical Society 38, 62.20.

Huestis, D. L., Slanger, T. G., Sharpee, B. D., Fox, J. L., 2010. Chemical origins of the Mars ultraviolet dayglow. Faraday Discuss. 147, 307. doi:10.1039/c003456h.

Jain, S. K., Bhardwaj, A., 2012. Atomic oxygen red, green, and ultraviolet line emissions in the dayglow of Mars. J. Geophys. Res. (submitted). 
Lawrence, G. M., 1972. Photodissociation of $\mathrm{CO}_{2}$ to produce $\mathrm{CO}\left(\mathrm{a}^{3} \pi\right)$. J. Chem. Phys. 56 (7), 3435 - 3442. doi: $10.1063 / 1.1677717$.

Lovell, A. J., Kallivayalil, N., Schloerb, F. P., Combi, M. R., Hansen, K. C., Gombosi, T. I., 2004. On the effect of electron collisions in the excitation of cometary HCN. Astrophys. J. 613, $615-621$.

McKay, A. J., Chanover, N. J., Morgenthaler, J. P., Cochran, A. L., Harris, W. M., Russo, N. D., 2012a. Forbidden Oxygen Lines in Comets $\mathrm{C} / 2006$ W3 Christensen and C/2007 Q3 Siding Spring at Large Heliocentric Distance: Implications for the Sublimation of Volatile Ice. Icarus, $277-285$. doi:10.1016/j.icarus.2012.04.030.

McKay, A. J., Chanover, N. J., Morgenthaler, J. P., Cochran, A. L., Harris, W. M., Russo, N. D., 2012b. Observations of the forbidden oxygen lines in DIXI target Comet 103P/Hartley. Icarus. doi:10.1016/j.icarus.2012.06.020.

Mitchell, J. B. A., 1990. The dissociative recombination of molecular ions. Phys. Rept. 186, 215 - 248.

Morgenthaler, J. P., Harris, W. M., Scherb, F., Anderson, C. M., Oliversen, R. J., Doane, N. E., Combi, M. R., Marconi, M. L., Smyth, W. H., 2001. Large-aperture O[I] 6300 $\AA$ photometry of comet Hale-Bopp: Implications for the photochemistry of OH. Astrophys. J, 563, 451 - 461. doi: $10.1086 / 323773$.

Morrison, N. D., Knauth, D. C., Mulliss, C. L., Lee, W., 1997. High resolution optical spectra of the head of the comet C/1996 B2 (Hyakutake). Astro. Soc. Pac. 109, 676-681. doi: $10.1086 / 133931$.

Nee, J. B., Lee, L. C. 1984. Photoabsorption cross sections of $\mathrm{OH}$ at $115-183 \mathrm{~nm}$. J. Chem. Phys. 81, 31-36. doi: $10.1063 / 1.447387$.

Raghuram, S., Bhardwaj, A., 2012. Model for the production of CO Cameron band emission in comet $1 \mathrm{P} /$ Halley. Planetary and Space Science 63-64, 139-149. doi: 10.1016/j.pss.2011.11.011.

Rosén, S., Derkatch, A., Semaniak, J., Neau, A., Al-Khalili, A., Padellec, A. L., Vikor, L., Thomas, R., Danared, H., af Ugglas, M., Larsson, M., 2000. Recombination of simple molecular ions studied in storage ring : Dissociative recombination of $\mathrm{H}_{2} \mathrm{O}^{+}$. Faraday Discuss. 407 (115), 295-302. doi:10.1039/a909314a.

Rosén, S., Peverall, R., Larsson, M., Le Padellec, A., Semaniak, J., Larson, A., Strömholm, C., van der Zande, W. J., Danared, H., Dunn, G. H., Jun. 1998. Absolute cross sections and final-state distributions for dissociative recombination and excitation of $\mathrm{CO}^{+}(\mathrm{v}=0)$ using an ion storage ring. Phys. Rev. A 57 (6), 4462-4471. doi: 10.1103/PhysRevA.57.4462.

Schleicher, D. G., Lederer, S. M., Millis, R. L., Farnham, T. L., Mar. 1997. Photometric behaviour of Comet HaleBopp (C/1995 O1) before perihelion. Science 275, 19131915. doi:10.1126/science.275.5308.1913.
Schultz, D., Li, G. S. H., Scherb, F., Roesler, F. L., 1992. Comet Austin $(1989 \mathrm{c} 1) \mathrm{O}\left({ }^{1} \mathrm{D}\right)$ and $\mathrm{H}_{2} \mathrm{O}$ production rates. Icarus 96 (2), 190-197. doi:10.1016/0019-1035(92)90072-F.

Seiersen, K., Al-Khalili, A., Heber, O., Jensen, M. J., Nielsen, I. B., Pedersen, H. B., Safvan, C. P., Andersen, L. H., 2003. Dissociative recombination of the cation and dication of $\mathrm{CO}_{2}$. Phys. Rev. A 68. doi:10.1103/PhysRevA.68.022708.

Singhal, R. P., Bhardwaj, A., 1991. Monte Carlo Simulation of Photoelectron Energization in Parallel Electric Fields: Electroglow on Uranus. J. Geophys. Res. 96, 15963 - 15972. doi:10.1029/90JA02749.

Slanger, T. G., Cosby, P. C., Sharpee, B. D., Minschwaner, K. R., Siskind, D. E., Dec. 2006. $\mathrm{O}\left({ }^{1} \mathrm{~S} \rightarrow{ }^{1} \mathrm{D},{ }^{3} \mathrm{P}\right)$ branching ratio as measured in the terrestrial nightglow. J. Geophys. Res. 111, 12318. doi:10.1029/2006JA011972.

Slanger, T. G., Sharpee, B. D., Pejaković, D. A., Huestis, D. L., Bautista, M. A., Gattinger, R. L., Llewellyn, E. J., McDade, I. C., Siskind, D. E., Minschwaner, K. R., 2011. Atomic oxygen emission intensity ratio: Observation and theory. Eos Trans. Vol. 92. AGU, pp. $291-292$.

Slanger, T. G., Sharpless, R. L., Black, G., 1977. CO 2 photodissociation, 1060 - $1175 \AA$ A. J. Chem. Phys. 66, 5317 5323. doi:10.1063/1.434710.

Storey, P. J., Zeippen, C. J., 2000. Theoretical values for the [OIII] 50007/4959 line intensity ratio and homologous cases. Mon. Not. R. Astron. Soc. 312, 813-816. doi:10.1046/j.13658711.2000.03184.x.

Tobiska, W. K., 2004. SOLAR2000 irradiances for climate change, aeronomy and space system engineering. Adv. Space Res. 34, 1736 - 1746. doi:10.1016/j.asr.2003.06.032.

van Dishoeck, E. F. and Dalgarno, A., 1984. The dissociation of $\mathrm{OH}$ and $\mathrm{OD}$ in comets by solar radiation. Icarus 5, 305313. doi:10.1016/0019-1035(84)90104-0.

Weaver, H. A., Feldman, P. D., A'Hearn, M. F., Arpigny, C., Brandt, J. C., Festou, M. C., Haken, M., McPhate, J. B., Stern, S. A., Tozzi, G. P., 1997. The activity and size of the nucleus of comet Hale-Bopp (C/1995 O1). Science 275, 1900-1904. doi:10.1126/science.275.5308.1900.

Wiese, W. L., Fuhr, J. R., Deters, T. M., 1996. Atomic transition probabilities of carbon, nitrogen, and oxygen: A critical data compilation. Am. Chem. Soc., Washington, D. C.

Woods, T. N., Feldman, P. D., Rottman, G. J., Mar. 2000. Ultraviolet Observations of Comet Hale-Bopp (C/1995 O1) by the UARS SOLSTICE. Icarus 144, 182-186. doi: 10.1006/icar.1999.6262.

Zhang, H. W., Zhao, G., Hu, J. Y., 2001. A catalogue of emission lines in spectra of comet C/1995 O1 (Hale-Bopp). Astron. Astophys. 367 (3), 1049-1055. doi:10.1051/00046361:20010008.

Zipf, E. C., 1969. The collisional deactivation of metastable atoms and molecules in the upper atmosphere. Can. J. Chem. 47, 1863-1870. doi:10.1139/v69-305. 